OPEN ACCESS

Edited by:

Xue-Jun Sun,

Second Military Medical

University, China

Reviewed by:

Francesco Angelico,

Sapienza University of Rome,

Guo-Dong Chen,

Jinan University, China

*Correspondence:

Yibin Feng

yfeng@hku.hk

Specialty section:

This article was submitted to

Ethnopharmacology,

a section of the journal

Frontiers in Pharmacology

Received: 31 December 2019 Accepted: 17 April 2020

Published: 12 May 2020

Citation:

Xu Y, Guo W, Zhang C, Chen F,

Tan HY, Li S, Wang N and Feng $Y$ (2020) Herbal Medicine in the

Treatment of Non-Alcoholic Fatty

Liver Diseases-Efficacy, Action Mechanism, and Clinical Application.

Front. Pharmacol. 11:601.

doi: 10.3389/fphar.2020.00601

\section{Herbal Medicine in the Treatment of Non-Alcoholic Fatty Liver Diseases- Efficacy, Action Mechanism, and Clinical Application}

\author{
Yu Xu, Wei Guo, Cheng Zhang, Feiyu Chen, Hor Yue Tan, Sha Li, Ning Wang \\ and Yibin Feng *
}

School of Chinese Medicine, Li Ka Shing Faculty of Medicine, The University of Hong Kong, Hong Kong, Hong Kong

Non-alcoholic fatty liver disease (NAFLD) is a common chronic liver disease with high prevalence in the developed countries. NAFLD has been considered as one of the leading causes of cryptogenic cirrhosis and chronic liver disease. The individuals with obesity, insulin resistance and diabetes mellitus, hyperlipidaemia, and hypertension cardiovascular disease have a high risk to develop NAFLD. The related critical pathological events are associated with the development of NAFLD including insulin resistance, lipid metabolism dysfunction, oxidative stress, inflammation, apoptosis, and fibrosis. The development of NAFLD range from simple steatosis to non-alcoholic steatohepatitis (NASH). Hepatic steatosis is characterized by fat accumulation, which represents the early stage of NAFLD. Then, inflammation triggered by steatosis drives early NAFLD progression into NASH. Therefore, the amelioration of steatosis and inflammation is essential for NAFLD therapy. The herbal medicine have taken great effects on the improvement of steatosis and inflammation for treating NAFLD. It has been found out that these effects involved the multiple mechanisms underlying lipid metabolism and inflammation. In this review, we pay particular attention on herbal medicine treatment and make summary about the research of herbal medicine, including herb formula, herb extract and naturals compound on NAFLD. We make details about their protective effects, the mechanism of action involved in the amelioration steatosis and inflammation for NAFLD therapy as well as the clinical application.

Keywords: non-alcoholic fatty liver disease, herb medicine, fatty acids, steatosis, inflammation

\section{BACKGROUND}

Non-alcoholic fatty liver disease (NAFLD) is a common chronic liver disease, and it is associated high metabolic risk of health problem such as dyslipidemia, insulin resistance, obesity and type II diabetic disease. In parallel with the prevalence of metabolic syndrome, NAFLD comprised of a spectrum of fatty liver that encompasses three typical pathological subtypes including liver steatosis, non-alcoholic steatohepatitis (NASH) and fibrosis. The least severe stage is simple liver steatosis induced by a largely build-up of fat in liver cell (Clapper et al., 2013). The progression of steatosis 
can be slowed or reversed by lifestyle modification and physical exercise. Otherwise, Non-Alcoholic Steatohepatitis (NASH), a severer form characterized by fat build-up, varying degrees of inflammation and ballooning degeneration of liver cells could be developed. More seriously, NASH continues to develop liver fibrosis and cirrhosis when the long term of liver injury leads to irreversible scarring of the liver (Bertot and Adams, 2019). As the late stage of fibrosis, Cirrhosis could irreversibly disrupt liver function and finally increased the risk of hepatocellular carcinoma development in patients.

Currently, there is no pharmacological agent that is being officially approved in NAFLD therapy. For one thing, the recommended intervention in NAFLD is lifestyle modification including energy intake restriction and physical activity enhancement. Lifestyle modification can reduce body weight and a moderate decrease of body weight could improve hepatic pathologic syndrome and decrease hepatic fat accumulation. For the other thing, some pharmacological interventions classified as antioxidants, insulin sensitizers and lipid-lowering drugs have been applied. For example, the antioxidant reagent such as Vitamin $\mathrm{E}$ has been suggested to treat non-diabetic patients with NASH as evidenced by a recent clinical trial (Sanyal et al., 2010); The use of lipid-lowering agents such as statin has been shown to reduce the risk of mortality or liver transplant in NAFLD patients (German et al., 2019); As sodium-glucose cotransporter 2 (SGLT2) inhibitors, Dapagliflozin and Canagliflozin could decrease hepatic lipid accumulation and significantly improve liver function (Arase et al., 2019). However, Most of these pharmacological agents are still at various stages of new drug development. For example, the natural farnesoid $\mathrm{X}$ receptor (FXR) agonist (obeticholic acid) and dual peroxisome proliferator-activated receptor $\alpha-\delta$ $(\operatorname{PPAR} \alpha-\delta)$ agonist (elafibranor), as well as glucagon-like peptide-1 antagonists were still investigated in phase IIA or IIB clinical trials (Sarwar et al., 2018). Meanwhile, several antidiabetic medications such as pioglitazone (Brunner et al., 2019), metformin and thiazolidinediones have been applied for the pharmacologic management of NAFLD in clinical practice due to their ability to reverse insulin resistance. Although the advances in conventional medicine, herbal medicine are easily accessible and do not require artificial synthesis, thus herbal medicine seems highly attractive for the effective management of NAFLD. Herbal medicine, defined as whole medicinal plants and unpurified plant extracts with medical properties, has been traditionally used in different countries of the world to improve liver conditions. A special term Traditional Chinese Medicine (TCM) was particularly given to refer to herbal medicines that have been applied since the ancient time of China, though TCM might also include medicines with origins of animals and minerals. TCM includes various forms of herbal medicine that has been proved to take effects on treatment of NAFLD. In recent years, progress in drug development of NAFLD has been found major advances with herbal medicines which are regarded as abundant sources of natural bioactive chemicals that improve hepatic functions. In this paper, we have provided an overview of herbal medicine (including herbal formula, crude extract, and pure bioactive compound form medicinal plants) approaches which have demonstrated their ability to counteract NAFLD in human patients and animal models.

\section{THE EFFECTIVE MANAGEMENT OF HERBAL MEDICINE ON NAFLD}

\section{Herbal Medicine Improve Hepatic Lipid Metabolism}

Overload lipid is the main initial reason that triggers hepatic steatosis. Excessive free fatty acids (FFAs) delivery from the adipose to the liver and result in the intrahepatic pool expansion of FFAs in the form of triglycerides. Fat accumulation evokes hepatic lipo-toxicity, which induces liver cells to release proinflammatory cytokines, trigger oxidative stress and hepatic stellate cell activation, ultimately lead to hepatic inflammatory injury. Improvement of fatty acid metabolism is an effective measure for in treating NAFLD, and the efficacy of herbal medicine targeting fatty acid metabolism has examined in both preclinical and clinical research of NAFLD. Firstly, The beneficial effects of herbal medicine on patients with liver dyslipidemia can improve lipid metabolic parameters such as decreasing the levels of triglycerides (TG), total cholesterol (TC) and low-density lipoprotein (LDL-C), alanine aminotransferase (ALT), aspartate aminotransferase (AST), as well as increasing the production of high-density lipoprotein (HDL-C). The interference of herbal medicine on dyslipidemia has been proved to be related to the regulation of fatty acid production or consumption. It has been found out that many herbal medicine (including herbal formula, crude extract and pure bioactive compound form medicinal plants) depressed the hepatic lipogenesis via reducing the expression of the key transcriptional factors and lipogenic enzymes such as Sterol Regulatory Element Binding Protein 1c (SREBP-1c), Peroxisome-Proliferator-Activated Receptor $\gamma$ (PPAR- $\gamma$ ), Acetyl-CoA Carboxylase (ACC), Fatty Acid Synthase (FAS) and SCD1. For example, Gypenosides (extracted from Gynostemma pentaphyllum) (Li et al., 2017a), the chloroform fraction of Cyclocarya paliurus (Lin et al., 2016), total alkaloids extracted from Rubus aleaefolius Poir. (Li et al., 2014b), Lonicera caerulea L. extract (Park et al., 2019) and the crude extract from the peels of Citrus aurantium L. (Rutaceae) (Han et al., 2019) effectively attenuates high fat diet (HFD) induced triglyceride accumulation via reducing the high production of SREBP-1c, PPAR- $\gamma$, FAS, and ACC.

\section{AMPK Pathway Involves in Herbal Medicine Modulation of Hepatic Lipogenesis and $\beta$-Oxidation}

Adenosine monophosphate-activated Protein Kinase (AMPK) is a key energy sensor of intracellular energy metabolism, which could cause the reduction of cellular triglyceride and cholesterol production. The activation of AMPK phosphorylation could attenuate free fatty acid-regulated de novo lipogenesis genes 
and hepatic lipid accumulation. AMPK phosphorylation have been mentioned frequently in hepatic lipid metabolism to be activated in response to many herbal medicine such as BaiHuJia RenShen Decoction (Liu et al., 2015a), Qushi Huayu Decoction (Feng et al., 2013), Lonicera caerulea L. extract (Park et al., 2019), nobiletin (a polymethoxylated flavonoid derived from citrus fruits) (Yuk et al., 2018), ginsenoside Rb1 (Shen et al., 2013), betulinic acid (Kim et al., 2019b), and berberine (Zhu et al., 2019). Sophocarpine (derived from foxtail-like sophora herb and seed) influences adipocytokine production via AMPK signaling in NASH rats (Song et al., 2013), and salvianolic acid B (isolated from Salvia miltiorrhiza Bge.) reduces dyslipidemia and hyperglycemia via AMPK activation (Huang et al., 2016). It has been reported that some herbal medicine such as Lonicera caerulea L. extract (Park et al., 2019) and methanolic extract of Alisma orientalis (Hong et al., 2006) increases fatty acid $\beta$ oxidation via activating lipid antioxidant enzymes such as Carnitine Palmitoyltransferase-1 (CPT-1) and lessening peroxidation. This beneficial effects of herbal medicine on $\beta$ oxidation involved the activation of AMPK/PPAR- $\alpha$ and its downstream pathway. For example, the methanolic extract of Alisma orientalis (Hong et al., 2006), the ethanol extract of Leonurus japonicus Houtt (Lee et al., 2017), Lycopus lucidus Turcz. ex Benth (Lee et al., 2019) and Hugan Qingzhi formula (Yin et al., 2014) increases hepatic $\beta$-oxidation via upregulation of the phosphorylated AMPK and PPAR $\alpha$ expression (Cao et al., 2016; Lee et al., 2017). AMPK activation in hepatic lipid $\beta$ oxidation also requires the activity of silent information regulator 1 (SIRT1), which interferes with PPARs activation. Silibinin shows its potential natural antioxidant effects on restoration of $\mathrm{NAD}^{+}$levels via AMPK/SIRT1 pathway. Licochalcone A (isolated from Glycyrrhiza uralensis) significantly induces the AMPK/SIRT-1 pathway to inhibit hepatic lipogenesis synthesis and improve $\beta$-oxidation (Liou et al., 2019). Dioscin mediated SIRT1/AMPK signal pathway and LXR $\alpha$ action (Cheng et al., 2018) to modulate the expression of SREBP-1c, CPT-1, FAS, SCD, FoxO1, and ATGL(Yao et al., 2018). Ursolic acid has been treated as a novel Liver $X$ receptor $\alpha$ (LXR $\alpha$ ) antagonist and Ursolic acid stimulated AMPK phosphorylation to inhibit steroid receptor coactivator-1 (SRC1) recruitment and promote small heterodimer partnerinteracting leucine zipper protein to the SREBP-1c promoter region (Lin et al., 2018). Thus, AMPK action activated by herbal medicine involves in de novo lipid synthesis associated with the suppression of SREBP-1c, FAS, ACC, and SCD-1expression, and increase $\beta$-oxidation defense that improves hepatic fatty acids efflux via the modulation of CPT-1 and PPAR $\alpha$ production.

\section{Oxidative Stress Action Involves in Herbal Medicine Modulation of Lipid Metabolism}

Oxidative stress reflected an imbalance between the reactive species production and antioxidant defense, which can lead to liver damage in the progression of NAFLD. The lipid metabolic disorder influences the production of reactive oxygen species (ROS), specifically, fatty acid $\beta$-oxidation seems to generate more ROS in NAFLD. The lipid lowering effect of herbal medicine shows its correlation with anti-oxidative stress action. For example, Bangpungtongseong-san attenuates the transcriptional response of oxidative phosphorylation (OXPHOS) in NAFLD liver (Choi J. Y. et al., 2019). Korea red ginseng shows anti-oxidant activity to improve hepatic lipid profiles in fatty rat (Hong et al., 2013). The ethyl acetate extract of Aristolochia manshuriensis Kom suppresses hepatic oxidative stress via improving the SOD, GR and GPx enzymes, subsequently increases hepatic lipid peroxidation of CYPE21 to promote hepatic lipolysis (Kwak et al., 2016). LiGanShiLiuBaWei San can significantly promote fatty acid oxidation via activation of $\operatorname{PPAR} \alpha$ and $\operatorname{PPAR} \beta$, and reduce oxidative stress via the inhibition of iNOS production (Jiang et al., 2015). The down-regulation of hepatic HO-1, NF-E2-related factor 2 (Nrf2), and SOD2 as well as up-regulation KEAP1 were detected in the NAFLD models, and the expression of these oxidative stress markers can be all reversed by Dioscin (Liu et al., 2015b). The Nrf2 activation mediated by herbal medicine can improve NAFLD via inhibiting oxidative stress pathway. It has been reported that scutellarin (a flavonoid glycoside), swertiamarin (a secoiridoid glycoside) (Yang Y. et al., 2019) and gastrodin (isolated from Gastrodia elata $\mathrm{Bl}$ ) enhance Nrf2-mediated antioxidant system via activating the mRNA and protein levels of PPAR $\gamma$ and its coactivator-1 $\alpha$, HO-1, GST, and NQO1 expressions (Ahmad et al., 2019), thus ameliorate NAFLD. Isochlorogenic acid B [extracted from Laggera alata (Asteraceae)] shows its protective effects on fibrosis in NASH by Nrf2 signaling pathway, and reverse the downregulation of miR-122 level and upregulation of hepatic HIF-1 $\alpha$ expression to inhibit multiple profibrogenic factors (COL1 $\alpha 1$, MCP-1, LOX, TGF- $\beta 1$, and TIMP-1) (Liu et al., 2019c).

\section{Mitochondria Function Involves in Herbal Modulation of Hepatic Lipid Metabolism}

Mitochondria plays a specialized role in lipid metabolism and could contact lipid droplets via Mitochondria oxidation in liver. Mitochondria dysfunction contribute to the progression of NAFLD since it influences hepatic lipid metabolism, promote the generation of ROS, and lipid peroxidation. Previous research has proved that herbal medicine such as cyclocarya paliurus, sida rhomboidea.roxb, punica granatum L., resveratrol, mangosteen pericarp, epigallocatechin gallate, and shexiang baoxin pill, were shown to be effective on mitochondrial dysfunction during treating the NAFLD (Yang X. et al., 2019). More detail, Shizukaol D (extracted from Chloranthus japonicas) improved mitochondrial dysfunction, leading to hepatic AMPK-dependent lipid content reduction ( $\mathrm{Hu}$ et al., 2013). Polygonati Rhizoma and Polygonatum kingianum promote mitochondrial $\beta$ oxidation via increasing the CPT-1 activity to block long-chain fatty acid enter mitochondria, and improve mitochondrial function via inhibiting HFD-induced excessive production of ROS and malondialdehyde (MDA) (Yang X. et al., 2019). Nobiletin (Qi et al., 2018) and diosgenin (Fang et al., 2019) could lead to the reduction of ROS level and restoration of mitochondrial membrane potential. This mitochondrial interference suppressed lipid peroxidation that involved the increase of vital scavenger levels of glutathione peroxidase (GSH-Px) and superoxide dismutase (SOD). Dioscin (isolated 
from Polygonatum Zanlanscianense Pamp) has been proved to increase the expression of SOD, GSH and GSH-Px, and decrease the production of iNOS, MDA and NO. Puerarin (extracted from Radix Pueraria lobate) evoked the activation of PARP-1/PI3K/ AKT signaling that facilitated the transcripts (Acox1, MCAD, Cpt1 and Cox5a) in $\beta$-oxidation and reversed the decreased level of mitochondrial respiration complex I and II activities, further improved the fatty acid metabolism (Wang S. et al., 2019).

\section{Bile Acid Synthesis Involves in Herbal Medicine Modulation of Lipid Metabolism}

Bile acids are synthesized in the liver and act as biological detergent to metabolite lipids and cholesterol into the bile. Gypenosides (extracted from Gynostemma pentaphyllum) (Li et al., 2017a), palmatine and jatrorrhizine (extracted from Coptidis Rhizoma) promote bile acid synthesis to prevent NAFLD, which involved the expression of cholesterol $7 \alpha$ hydroxylase A1 (CYP7A1). Punicalagin and pomegranate ellagic acid (isolated from Punica granatum L.) activate the CYP7A1/PPAR $\gamma$ signaling to promote hepatic diversion of cholesterol into bile acid (Ji et al., 2019). Celastrus orbiculatus Thunb. accelerated the hepatic cholesterol excretion in guinea pigs through suppressing oxidative stress via upregulation of the mRNA abundance of 3-hydroxy-3-methyl-glutaryl-CoA reductase (HMG-CoAR) and CYP7A1 (Zhang et al., 2013). Glycyrrhizin (extracted from Glycyrrhizae Radix Et Rhizoma) modulated serum bile acid metabolism in MCD diet-fed mice by restoring inflammation-mediated hepatic farnesoid $\mathrm{X}$ receptor (FXR) inhibition (Yan et al., 2018). The modulation of herbal medicine on lipid and cholesterol absorption and transport involved the bile acid regulation and shows its beneficial effects on treating NAFLD.
Above all, we provided an important lipid mechanistic insight into the anti-NAFLD effects of herbal medicine, which was shown in Figure 1. The commonly used herbal medicine inhibited fatty acid or diet-induced lipogenesis via SREBP-1c pathway and promoted the lipolysis focusing on fatty acid $\beta$ oxidation, which involved oxidative stress and mitochondrial function. The underlying mechanism of action might be achieved through the modulation of AMPK signaling pathway (Ding et al., 2019).

\section{Herbal Medicine Ameliorates the Hepatic Inflammation}

Hepatic inflammation promotes lipid deposition and redistribution from adipose to liver and drives liver inflammatory injury. Hepatic inflammation triggers the development of NAFLD from hepatic steatosis to steatohepatitis and fibrosis (Marra and Lotersztajn, 2013). Amelioration of heaptic inflammation is vital for NAFLD therapy. It has been indicated that herbal medicine has exerted the protective effects against the progression from hepatic steatosis to steatohepatitis and the underlying mechanism have been proved to be involved in inhibiting the inflammatory signaling pathway as shown in Figure 2, thereby regulating dyslipidemia and improving liver function in NAFLD. Many herbal medicine (including herbal formula, crude extract and pure bioactive compound form medicinal plants) possessed antiinflammatory properties for slowing down the NAFLD progression, such as Sinai san dection (Zhang et al., 2005), Hugan Qingzhi tablet (Tang et al., 2015), betulinic acid (Kim et al., 2019b), Alisma orientalis (Choi E. et al., 2019), gastrodin (Ahmad et al., 2019), the peel extract of Citrus aurantium L. (Rutaceae) (Han et al., 2019) and swertiamarin (Yang Y. et al.,

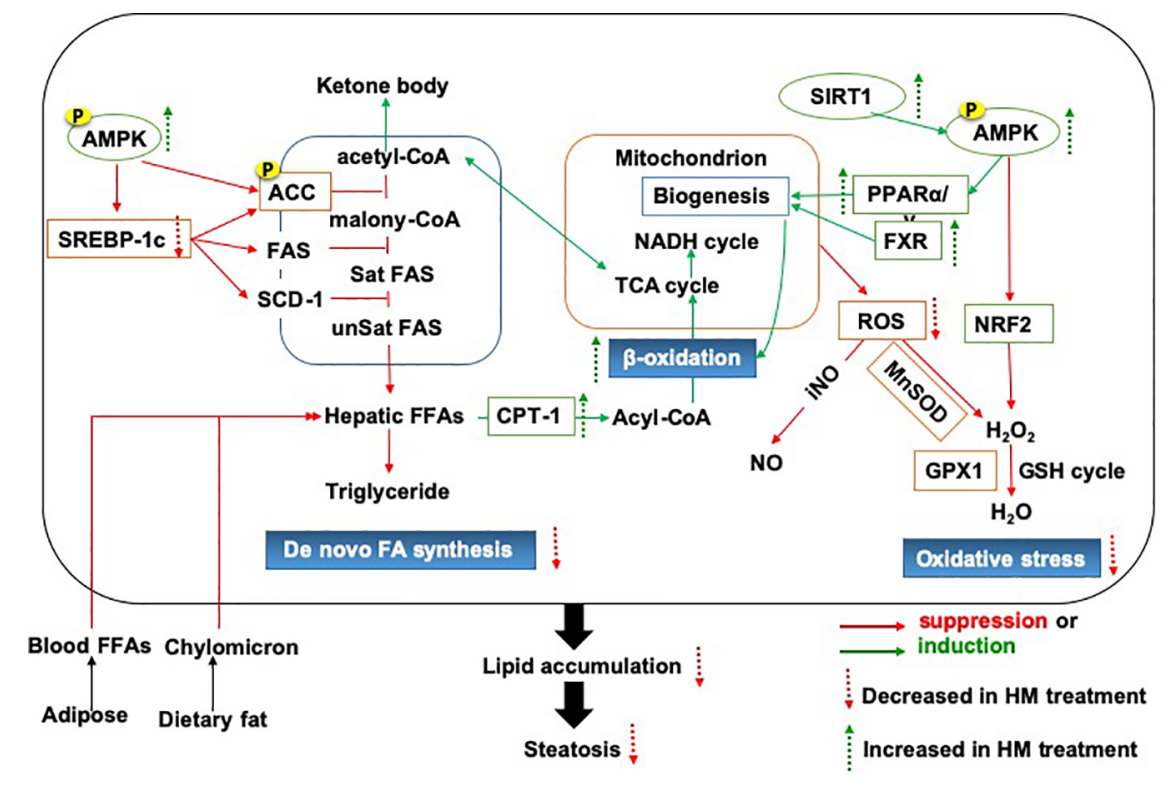

FIGURE 1 | The lipid mechanistic insight into the anti-NAFLD effects of herbal medicine. NAFLD, Non-alcoholic fatty liver disease. 


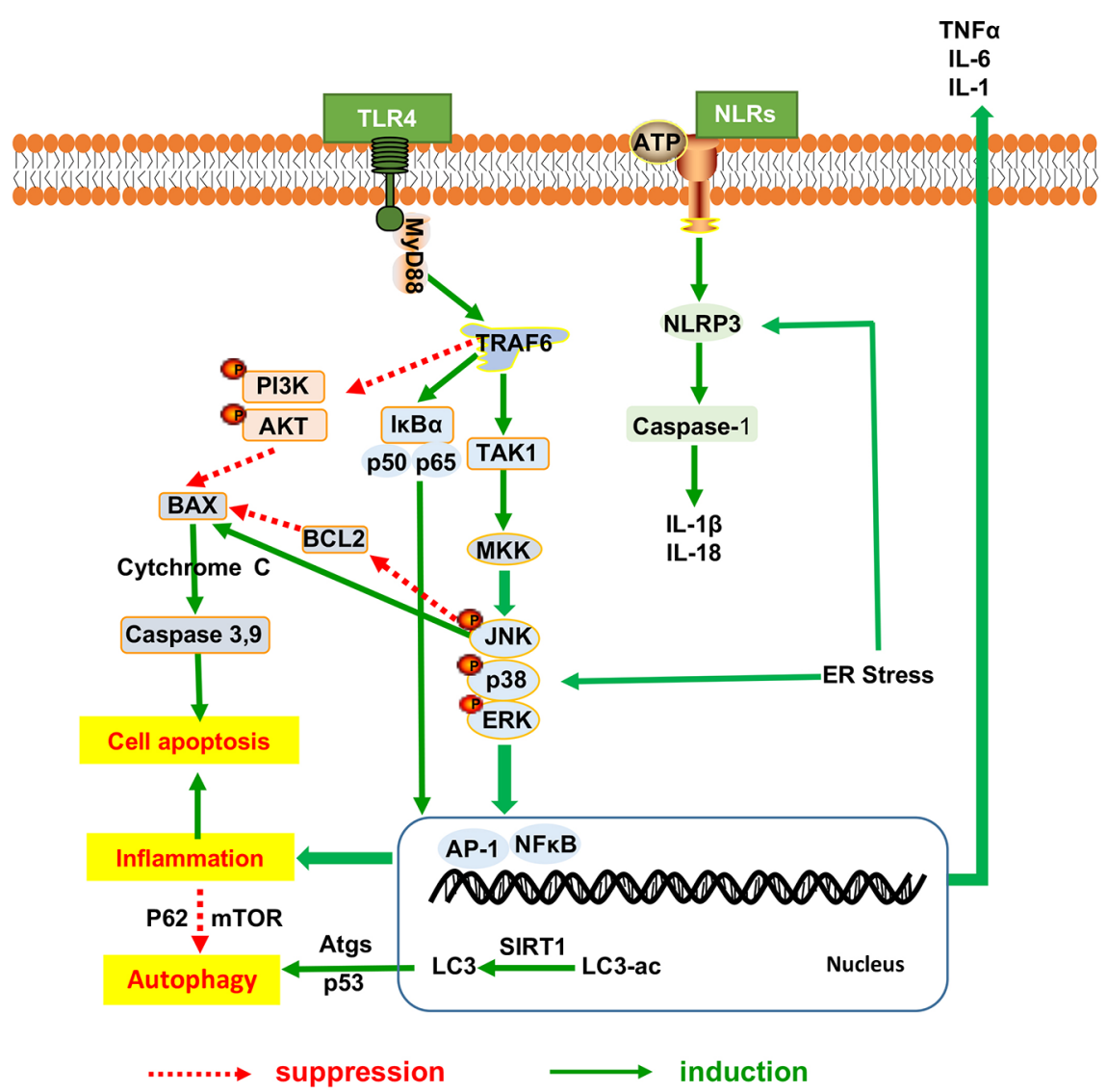

FIGURE 2 | The inflammatory mechanistic insight into the anti-NAFLD effects of herbal medicine. NAFLD, Non-alcoholic fatty liver disease.

2019), and all of these medicine reduces the expression levels of hepatic inflammatory cytokines (TNF $\alpha$, IL-6, and IL1 $\beta$ ). Baicalin (extracted from Scutellaria baicalensis Georgi) (Zhang J. et al., 2018) and aqueous extract of Salvia miltiorrhiza Bunge (Hong et al., 2017) show the anti-inflammatory action, further improve liver fibrosis by inhibition of $\alpha$-SMA, Col1A1, and TGF$\beta 1$ production.

\section{NF-אB Pathway Involves in Herbal Medicine Modulation of Hepatic Inflammation}

We found out that the NF- $\mathrm{KB}$ signaling mentioned frequently in the anti-inflammatory response of herbal medicine in treating NAFLD. Jianpi Huoxue formula (Feng et al., 2019), baicalin (Zhang J. et al., 2018) and Lycium barbarum polysaccharides showed ameliorative effects on hepatic inflammatory response involved with the reduction in Monocyte Chemotactic Protein-1 (MCP-1) expression, macrophage influx and hepatocyte apoptosis, partially owing to its power to suppress nuclear factor- $\kappa \mathrm{B}(\mathrm{NF}-\kappa \mathrm{B})$ activation and the autophagic process of cleaved caspase-3 (Xiao et al., 2014; Zhai et al., 2015). Moreover, as a necessary prerequisite for triggering other inflammasome, the NF- $\mathrm{KB}$ signaling medicated the regulation of other inflammasome including NLRP3, the toll-like receptors and apoptosis mediators, all of which has been proved to be involved in the anti-inflammatory research of herbal medicine for NAFLD. Firstly, the palmitate acid-induced hepatocytes steatosis involved the activation of NLRP3 inflammasome and increased secretion of IL- $1 \beta$ and IL-18. And the NOD-, LRR- and pyrin domain-containing protein 3 (NLRP3) activation can be reversed by nobiletin and andrographolide (extracted from Andrographis paniculata (burm.f.)Nees) (Cabrera et al., 2017), as described by the downregulation of Caspase1, IL1 $\beta$ and IL18 expression via a NF- $\kappa \mathrm{B}$-dependent mechanism (Askari et al., 2014). Secondly, TLRs initiated signaling by binding to Myeloid Differentiation primary-response protein 88 (MyD88) triggers recruitment of TRAF6, TAK1, and MKK, which thereby activated the downstream signaling pathway of the extracellular signal-regulated kinase (ERK), p38MAPK, and cjun $\mathrm{N}$-terminal kinase (JNK). This activity leads to NF- $\mathrm{BB}$ nuclear translocation and the induction of gene transcription mediated by proinflammatory cytokines and chemokines. Tolllike receptors (TLRs) signaling pathways have been proved to participate in the anti-inflammatory response of herbal medicine in treating NAFLD. BuShenKangShuai tablet improved liver adiponectin resistance via inhibiting TLR4/NF- $\kappa \mathrm{B}$ p65 signaling pathway, followed by the inhibition of TNF- $\alpha$, IL-1 $\beta$, 
MCP-1 and Vascular Vell Adhesion Molecule-1(VCAM-1), as well as the promotion of interleukin-10 and adiponectin production (Pang et al., 2019). Sparstolonin B (derived from Sparganium stoloniferum Buch.-Ham.) attenuated liver fibrosis through antagonizing TLR4 induced TGF- $\beta$ signaling. Sparstolonin B augmented the hepatic TGF $\beta$ pseudo-receptor expression in mice, leading to downregulation of extracellular matrix deposition and hepatic stellate cell activation (Dattaroy et al., 2018). Moreover, Sparstolonin B obviously inhibited Kupffer cell activities as evidenced by the decrease in MCP-1 and CD68 levels with concomitant suppression of macrophage infiltration via blocking NADPH oxidase-driven TLR4 trafficking to the lipid rafts in NASH (Dattaroy et al., 2016). Dioscin rehabilitated inflammation (Liu et al., 2015b) that was associated with the decreased expression levels of p50, p65, and $\mathrm{I} \kappa \mathrm{B} \alpha$ via regulation of MyD88-dependent TLR4 signaling pathway (Zhang E. et al., 2016; Yang L. et al., 2019). Garlicderived S-allylmercaptocysteine mitigated NAFLD-induced inflammation via the restoration of the phosphorylated FFAsdependent mitogen-activated protein kinases (MAPKs) and diminishment of the AP-1 and NF- $\mathrm{KB}$ activation (Xiao et al., 2013a). Berberine prevent NASH-derived hepatocellular carcinoma in mice via suppressing the phosphorylation of p38MAPK, ERK and COX2 expression (Luo et al., 2019).

\section{Apoptosis Signaling Involves in Herbal Medicine Modulation of Hepatic Inflammation}

The interference with the TLR mediated inflammatory response has proved to be involved into intracellular apoptosis signaling. These have been supported by the evidence that total aralosides from aralia elata (Miq) seem protected mice against HFDinduced cellular apoptosis, as suggested by TUNEL staining, and ameliorated NASH by inhibiting the NF- $\kappa \mathrm{B} / \mathrm{IRE} 1 \alpha / \mathrm{JNK} /$ $\mathrm{I} \kappa \mathrm{B}$ activation in $\mathrm{ApoE}^{-/-}$mice (Luo et al., 2015); Lycium barbarum polysaccharides partially modulated hepatocyte apoptosis process via NF- $\mathrm{KB} / \mathrm{MAPK}$ pathways, which has been proved to be related to the biological activity of l-arabinose and $\beta$-carotene in polysaccharides (Xiao et al., 2014). Resveratrol and Sparstolonin B exerted a promising role on the modulation of cell proliferation and apoptosis via TLR4/phosphatidylinositol 3kinase- (PI3K-)/AKT signaling pathway (Dattaroy et al., 2016). Psoralea corylifolia L. inhibited NF- $\kappa \mathrm{B}$ activation in the portal area to alleviate inflammatory cell infiltration and fibroplasia, further enhanced PI3K/Akt signaling to reduce hepatic superoxide anion expression, and $\mathrm{NADPH}$ oxidase activity as well as p47(phox) protein level and PKC $\alpha$ activation (Zhou et al., 2017). Since the apoptosis signaling involves in herbal medicine modulation of hepatic inflammation, herbal medicine reduces the apoptotic cytokines such as caspases and Bcl-2 family proteins expression in the progression of hepatic inflammation. For instance, dioscin increased Bcl-2 production and blocked the activation of Bak, Caspase-3/9, FasL, Fas, p53 proteins via reducing IRF9 production against apoptosis (Liu et al., 2015b; Shen et al., 2015; Zhang W. et al., 2016). Polygonati Rhizoma could notably remedy mitochondrial apoptosis and alleviate HFD-induced NAFLD via increasing the expression levels of caspase 3, caspase 9, and Bax, while decreasing the Bcl-2 level in hepatocytes and cytchrome $\mathrm{C}$ in mitochondria (Yang et al., $2019 b$ ). Furthermore, herbal medicine showed an effective role in inhibition of apoptotic cytokines, partially involved in the JNK-induced hepatocyte apoptosis for the treatment of NAFLD/ NASH. Jianpi Huoxue formula (mainly consists of Atractylodis macrocephalae Rhizoma, Salvia miltiorrhizae Radix Et Rhizoma, Paeonia Radix Alba, Alismatis Rhizoma, and Schisandrae Chinensis Fructus) may have beneficial effects on MCD induced liver inflammation and apoptosis via the inhibition of the JNK phosphorylation and the activation of caspase 3 and 7 proteins (Feng et al., 2019). The ethyl acetate extract of Aristolochia manshuriensis Kom inhibited hepatic apoptosis via the suppression of ERK1/2 and JNK1/2 phosphorylation (Kwak et al., 2016); Silibinin (a flavonolignan from milk thistle) ameliorated various symptoms of NASH by activating death domain-like apoptosis regulator (CFLAR)-JNK pathway, and thereby modulated its downstream target genes to promote the fatty acid $\beta$-oxidation (PPAR $\alpha$, SREBP-1C, and PNPLA3), antioxidase action (CAT, HO-1, and GSH-Px) and inhibition of prooxidase action (NRF2, CYP4A, and CYP2E1) to ameliorate oxidative stress, as well as inflammatory response (Wang et al., 2017; Liu et al., 2018; Liu et al., 2019d). Therefore, activated hepatic apoptosis exerted a wide range of biological actions involved facilitating inflammation with oxidative stress modulation. And combined with the beneficial effects on liver steatosis, herbal medicine also relived the reliable growth in indicators of hepatocyte cytokine proinflammatory status, apoptosis, and fibrosis in the development of steatohepatitis.

\section{Autophagy Involves in Herbal Medicine Modulation of Hepatic Inflammation}

The lysosomal-mediated degradation process of autophagy is beneficial for removing the damaged cellular proteins and organelles, including mitochondria, peroxisomes, and endoplasmic reticulum (ER), thus the autophagy activation takes metabolic intermediates necessary for protein metabolism. And herbal medicine induced autophagy had been considered as an anti-inflammatory strategy to show the obvious effects on reducing the NAFLD progression. Resveratrol promoted the autophagy pathway to restore liver injury, which was linked with NF- $\mathrm{KB}$ activation (Ji et al., 2015); Lycium barbarum polysaccharides showed ameliorative effects on autophagic proteins (LC3II and Atg5), and deceased autophagic negative modulators (p62 and p-mTOR) via the NF-KB/MAPK pathways (Xiao et al., 2014). Herbal medicine rehabilitated inflammation, reduced apoptosis and enhanced autophagy through both extrinsic and intrinsic apoptotic pathways, thereby counteracting the effects of NAFLD. For example, Dioscin inhibits collagen synthesis through modulating the expressions of autophagic flux (P62 LC-I LCII) (Xu et al., 2017). Administration of Akebia saponin D (extracts from Akebia quinata) resulted in the upregulation of autophagic flux (e.g., decreased P62 accumulation and increased the level of LC3-II expression) in the liver of ob/ob mice (Gong et al., 2016); Glycycoumarin (a coumarin compound isolated 
from Rhizoma Glycyrrhizae) inhibited hepatocyte lipo-apoptosis through reactivation of impaired autophagy and inactivation of GSK-3. In line with autophagy activation, mitochondrial apoptotic activation, and ER stress-mediated JNK pathway were also blocked by glycycoumarin (Zhang A. et al., 2016); Nobiletin (Yuk et al., 2018), ginsenoside Rb2 (extracted from Panax Ginseng C.A.Mey) and Tangshen formula (Wang Y. et al., 2019), could reverse the repression of autophagic pathways in AMPK-SIRT1 dependent manner (Huang et al., 2017). The AMPK/SIRT1 pathway mediated the activation of fork head box transcription factors that increased Atg proteins production, additionally, SIRT1 could combine with Atgs (Atg7 and Atg8) to form a molecular complex to deacetylate the core autophagy machinery. Resveratrol (a pharmacological SIRT1 activator) significantly prevented hepatocyte ballooning and steatosis, along with the changed levels of LC3-II, Beclin 1, and P62, as well as ER stress (Ding et al., 2017). It could be confirmed that resveratrol potentiated SIRT1 secretion and its deacetylase activity, which decreased p53 and increased autophagy. Further studies demonstrated that the effect of resveratrol on hepatic steatosis was achieved partially via the cAMP-PRKA-AMPK-SIRT1 autophagy pathway (Zhang et al., 2015). Meanwhile, mTOR, another famous negative autophagic regulator, was decreased after some herbal treatments, such as Garlic-derived S-allylmercaptocysteine enhanced the levels of autophagic markers expression in the liver, with a concomitant decrease the mTOR activity (Xiao et al., 2013b).

\section{Herbal Medicine Triggers Other Pathways in NAFLD}

\section{Endoplasmic Reticulum (ER) Stress}

ER stress involved the increase of JNK and caspase-12 expression serves a primary role in the procession of NAFLD and pathogenesis to NASH. The pharmacological activation of FXR induced by betulinic acid alleviated the hepatic ER stressmediated hepatic steatosis (Gu et al., 2019). The farnesoid X receptor (FXR) activation suppresses the expression of ER stress markers (PERK, EIF2 $\alpha$ and ATF4) and CHOP signaling, thereby reducing hepatocellular ER stress. Betulinic acid could serve as an FXR agonist that effectively attenuates the pathogenesis of HFD and MCD induced NAFLD, and Alisma orientalis could restore the hepatocellular ER homeostasis by stimulating the FXR activation, particularly, Alisol A 24 (B 23)-acetate accounts for this action (Choi E. et al., 2019).

\section{Insulin Signaling Pathway}

Insulin-induced insulin receptor phosphorylation recruited the insulin receptor substrate-1 (IRS-1) and subsequently activated phosphoinositide 3-kinase (PI3K)/AKT pathway, leading to the activation of PKA and SGK-3 $\beta$ and ultimately encouraging glycogen and lipolysis synthesis, and subduing gluconeogenesis and lipogenesis (Kwon et al., 2018). Naringenin (Mulvihill et al., 2009), Ginsenoside Rb1(Yu et al., 2015) and Leonurus japonicus Houtt extract (Lee et al., 2017) prevented hyperinsulinemia, leading to the correction of NAFLD associated metabolic disturbance that was linked to glucose utilization and insulin sensitivity (Lee et al., 2017). It has been found that nobiletin (Kim et al., 2017) and ursolic acid (Li et al., 2014a) ameliorated insulin resistance and takes effects on amplifying glucose uptake through IRS-1/AKT stimulation (Yuk et al., 2018) in treatment of NAFLD; Jwa Kum Whan ameliorated insulin resistance and reduced hepatic triglyceride and cholesterol accumulation via significant triggered the phosphorylation of IRS-1 and PI3K (Lim et al., 2019). The potential underlying mechanism of Erchen decoction for the treatment of obesity, hyperlipidemia and fatty liver is to increase the CDKAL1 production, improve islet cell function and insulin level (Gao et al., 2015). A related study indicated that yangonin increased insulin sensitivity via increasing the expression of phosphorylated IRS-1 and IRS-2 (Dong et al., 2019).

\section{Herbal Medicine Induced Gut Microbiota Alteration in NAFLD}

It has been suggested that gut dysbiosis in patients have different shift in the development of NAFLD. There is an inverse association between the presence of NAFLD and the abundance of Bacteroidetes in gut microbiota, indicating that the intestine microbiota takes a vital role in the progression of NAFLD (Mouzaki et al., 2013). Therefore, the modulation of intestine microbiota has become a potential therapeutic strategy for the treatment of NAFLD. Supplementation of prebiotic, probiotic compounds, or herbal medicine (Porras et al., 2017), have taken a modulatory effect on the intestine microbiota. Lingguizhugan decoction reduced hepatic steatosis and improved glycemic control through the modulation of gut microbiota (Liu et al., 2019b). Microbiome analysis revealed that herbal formula shenling baizhu powder promoted the relative percentage of short-chain fatty acid-producing microbiota, such as Bifidobacterium and Anaerostipes (Zhang Y. et al., 2018). Mechanistic studies found that herbal formula such as shenling baizhu powder alleviated hepatic steatosis and repaired colon mucosa via decreasing the expression level of endotoxin and inflammatory mediators (TNF- $\alpha$, IL-1 $\beta$ ) via the TLR4 pathway (Zhang Y. et al., 2018b). Diammonium glycyrrhizinate is a medicinal form of glycyrrhizic acid and has been proved to modify gut microbiota composition to decrease the intestinal low-grade inflammation and restore intestinal barrier function in NAFLD mice. Diammonium glycyrrhizinate reduced the abundance of the endotoxin-producing bacteria such as Desulfovibrio and elevates the level of probiotics such as Lactobacillus and Proteobacteria, as well as augmented the abundance of short-chain fatty acid (SCFA)-producing bacteria such as Ruminococcaceae and Lachnospiraceae to promote SCFA production (Li et al., 2018).

\section{Clinical Application of Herbal Medicine on NAFLD}

In the clinical setting, clinical trials could confirm the experimental benefits of herbal medicine application in NAFLD patients. Clinical trials for NAFLD have been seen improvement with herbal medicine therapy. Randomized controlled trials comparing either herbal medicine alone or in 
combination with other interventions or pharmaceutical agents have been investigated and the results indicated that herbal medicine had a better effect on the normalization of AST and the disappearance of radiological steatosis in the treatment of NAFLD patients (Shi et al., 2012). For instance, the daily consumption of resveratrol plus with lifestyle modification for 12 weeks showed superior effect than lifestyle change alone. Meanwhile, after resveratrol supplementation, the decreased level of insulin resistance, ALT, AST, LDLC, TC, and TNF- $\alpha$ were showed in NAFLD patients (Berman et al., 2017). It is essential to prove the efficacy and safety of herb medicine in treating NAFLD, because the side-effects of herb medicine need to be confirmed and investigated further (Rahmani et al., 2016) in clinical application. Because some herbal medicines such as Phyllanthus urinaria L. that has been suggested as the hepatoprotective herb in animal studies showed unsatisfactory effect in improving NAFLD activity score in NASH patients (Wong et al., 2013). The development of Radom Control Trials for herbal medicine is important and essential for making validation about the efficacy of herbal medicine in treating NAFLD. We made summery about the clinical trials about the effective herbal medicine (including herbal formula, crude extract and pure bioactive compound form medicinal plants) that have proved to take positive effects on the biochemical and physiological features of NAFLD (Liu et al., 2013).

\section{Herbal Formula Against NAFLD}

According to Chinese Medicine theory and prescription principles, the herbal formula is developed with selection of appropriate medicinal plants and the dosage of each herb for treating patients with NAFLD. The meta-analysis of 62 randomized controlled trial was conducted to investigate the herbal medicine therapy for NAFLD. It indicated that 246 Chinese herbs have been found to be included and clinical applied for NAFLD with an average of ten species in each formulation. It was found out that herbal medicine take effective action on the therapy of NAFLD, and Crataegi Fructus (Shan-Zha) was the most common used herbal medicine for 321 times in 17,670 patients (Shi et al., 2012). Many herbal formulas have been reported to show anti-NAFLD function in clinical application. For example, Yinchenhao Decoction has been used in treatment of gallbladder and liver diseases for centuries and it was composed of Artemisia capillaris (Thunb), Gardenia jasminoides (Ellis), and Rheum palmatum (L) (Yao et al., 2016); Oral administration of Danning Tablet (composed of Rhei Radix Et Rhizoma, Polygoni Cuspidati Rhizoma Et Radix, dried green orange peel and dried old orange peel) for three month in 232 patients can improve the clinical symptoms of NAFLD (Fan, 2004); The results of metaanalysis showed that HuoXueHuaYu improved B ultrasonic level in patients with NAFLD. As to lipids, HuoXueHuaYu showed effective action on reduction of TC, TG, ALT, and AST levels (Cai et al., 2019); Bangpungtongseong-san is an ancient Chinese herbal medicine formula and has been clinically applied in Korea, Japan (Bofu-tsusho-san), and China (Fang feng tong sheng-san) for obesity and its associated metabolic syndrome (Kobayashi et al., 2017); Erchen Decoction is used for the treatment of obesity, hyperlipidemia, and fatty liver diseases. Seven randomized controlled trials with a total of 1951 participants were investigated for the effects of Erchen Decoction on patients with NAFLD. The meta-analysis results of Erchen Decoction investigation showed that patients receiving Erchen Decoction with conventional treatment showed more effective in clinical improvement of NAFLD compared with conventional treatment alone (Li et al., 2017b); The Dava ALbalgham (composed of Nigella Sativa, Zataria Multiflora, Trachyspermum ammi, Pistacia lentiscus have shown antiinflammatory, anti-atherogenic, and anti-oxidant effects. A double blind randomized trial of Dava AL-balgham has been applied for 76 patients with fatty liver disease. After three month treatment, Dava AL-balgham could improve the serum level of liver enzymes in patients with fatty liver (Hormati et al., 2019).

\section{Single Herb Against NAFLD}

The meta-analysis was performed to confirm the efficiency and safety of Salvia miltiorrhiza Bunge (Danshen) in eight randomized controlled trials with 800 patients. It indicated that Salvia miltiorrhiza Bunge showed positive effects on the levels of ALT, AST, TC and TG, LDL, and liver/spleen computed tomography ratio in patients with NAFLD. Future randomized clinical trials of higher quality are still required to evaluate the efficacy and safety of Salvia miltiorrhiza Bunge in NAFLD (Peng et al., 2016). Panax Ginseng C.A.Mey has been often applied against multiple metabolic conditions, including hepatosteatosis, Korean Red Ginseng shows anti-inflammatory and anti-fatigue effects on 80 patients with NAFLD (Hong et al., 2016).

\section{Pure Natural Compound Against NAFLD}

Curcumin (a natural polyphenol from Curcuma longa L.) owed the lipid-modifying, anti-inflammatory and antioxidant properties. Panahi et al. reported a randomized placebo controlled trial of curcumin in 87 subjects with NAFLD (Panahi et al., 2017) and concluded that daily supplementation of curcumin for 8 weeks decreased liver lipid accumulation and the levels of AST and ALT in patients of NAFLD without any issues of tolerance (Liu et al., 2019a). Diammonium glycyrrhizinate, a medicinal form of glycyrrhizic acid possesses anti-inflammatory and antioxidant effects. It has been applied for the treatment and control of chronic hepatopathy including NAFLD(Li et al., 2018); Cinnamon (Blevins et al., 2007) showed the improvement of the serum glucose and lipid levels in people with non-insulin dependent type 2 diabetes mellitus (NCT00237640). Further studies with 50 patients NAFLD were tested to investigate whether Cinnamon exerts the insulin sensitizer action in NAFLD patients. The results showed that daily intake of Cinnamon (1.5 g) for 12 weeks has beneficial effects on lipid profile, insulin resistance, liver enzymes, and high-sensitivity C-reactive protein in NAFLD patients (Askari et al., 2014). Ginger possess strong antioxidant ability to reduce lipids peroxidation (Si et al., 2018). The Early Phase I clinical investigation of Ginger in treatment of NAFLD in patients with type 2 diabetes mellitus (NCT02289235) is in progress to test whether Ginger takes effects on the liver biomarkers (ALT, AST, 
and $\gamma$-glutamyl transpeptidase) and fatty liver score in fibro-scan. A multi-center, phase III, double-blind clinical trial reported that oral administration of silybin combined with phosphatidylcholine and vitamin E for 12 months can improve insulin resistance, liver enzymes, and liver histology (Loguercio et al., 2012). The clinical trial study of Silymarin (IRCT201202159018N1) was conducted on 64 patients with $\mathrm{NASH}$ and after 8 weeks treatment, the patients with NASH experience obvious fall in hepatic enzymes (Solhi et al., 2014).

\section{Others}

At present, the clinical trials recorded in U.S. National Library of Medicine mentioned the herbal medicine in treating NAFLD includes YiQiSanJu formula (NCT01677325, Phase I completed), Phyllanthus urinaria (NCT01210989, N/A completed), Zhenzhu Tiaozhi capsules (NCT03375580, N/A Recruiting), Fermented ginseng powder (NCT03260543, N/A completed), Trigonella Foenum-graecum Seed Extract (NCT02303314, Phase II, and III completed), Zataria Multiflora Boiss. (Shirazi's thyme) (NCT02983669, N/A completed), and Ginger (NCT02535195, Phase II and III completed), as well as some bioactive natural compounds such as Berberine (NCT04049396, NCT03198572 Recruiting, Phase IV), Curcumin (NCT03864783, Recruiting), Silymarin (NCT02006498, Phase II completed and NCT02973295, Phase IV Recruiting), Resveratrol (NCT02030977, Phase II and III completed; NCT01464801, N/A completed; NCT01446276 N/A completed), Anthocyanin (NCT01940263, Early Phase I completed), Pioglitazone and Berberine (NCT00633282, phase II Completed), Anthocyanin (NCT01940263, phase II Completed) and Siliphos (NCT00443079, phase II Completed).

\section{Conclusion and Discussion}

Following the general requirement of the pharmacological research of herbal medicine (Heinrich et al., 2020), we firstly made assessment of the pharmacological research literature on herbal medicine, focusing on the experiment design, we checked the methodological details such as group size, controls and animal species. Specifically, we observed the dosage, route and frequency of drug administration in the research literature, and checked the tested dose range that should be pharmacological relevant. After the assessment, the literature of herbal medicine that reach the general requirement of the pharmacological research are included in our review. As shown in Table 1, a large number of natural compounds, whole extract and herb formula have been widely investigated against different pathologies of NAFLD with promising results (Porras et al., 2018). Increasing evidence has shown polyphenols (Porras et al., 2018) including resveratrol (Aguirre et al., 2014), quercetin (green tea, soy isoflavones) silymarin (extracted from Sylbum marianum), silybin and rutin (Van De Wier et al., 2017) are the frequently investigated natural compounds, along with the satisfactory effectiveness in NAFLD. As shown in Figure 3, herbal medicine mediated the key pathological events in the procession of NAFLD include lipid metabolism dysfunction, insulin resistance, fibrosis, oxidative stress, inflammation, and apoptosis (Wang et al., 2016). The satisfactory improvement of NAFLD disease outcomes and endpoints mentioned the amelioration or reduction of fat mass, insulin resistance, serum level of FFA, AST, and ALT, hepatic lipid accumulation and fibrosis, as well as hepatic oxidative stress, inflammatory response, and apoptosis. Thus, we made a review of the usage and role of herbal medicine in NAFLD. Steatosis, characterized by fat accumulation, represented the early stage of NAFLD and inflammation that interfered with the insulin signaling pathway is the key process that makes early steatosis develop into steatohepatitis (Bai and Li, 2019). Therefore, amelioration of steatosis and inflammation is vital for NAFLD therapy. Herbal medicine therapy has shown promising anti-inflammatory, antioxidant, and anti-apoptotic properties that might take beneficial effects on curtailing the inflammatory progression of NAFLD. Their action was always involved in multi-pathways to improved NAFLD, such as baicalin exerted anti-inflammation and anti-oxidant effects that can reduce hepatic lipid accumulation, suppress induced hepatic inflammation, and prevent liver fibrosis involved inhibiting hepatocyte apoptosis (Zhang J. et al., 2018). Gegenqinlian decoction influence NAFLD via improving PPAR $\gamma$ to inhibit inflammation and modulated lipid metabolism (Wang et al., 2015). Alisma orientalis protected against de novo lipogenesis to upregulate hepatic lipid export. Additionally, it modulated oxidative stress cytokines, inflammatory and fibrotic mediators, eventually influenced lipo-apoptosis and liver injury panels (Choi E. et al., 2019). Resveratrol can be considered as a pharmacological SIRT1 activator (Zhang et al., 2015) and take effects on hepatic steatosis by improving lipid-related gene transcriptional expression, oxidative stress and inflammation (Cheng et al., 2019), meanwhile decreasing ER stress (Ding et al., 2017) via the autophagy (Liu et al., 2015a). In addition, it has shown that herbal medicine combined with other interventions exhibited a much better beneficial effect than single interference alone. For example, Lingguizhugan decoction and calorierestriction therapy together could enhance the reduction of fasting blood lipid levels (Yuanyuan et al., 2015; Cao et al., 2016). The combination of Korean red ginseng and probiotic Lactobacillus synergistically ameliorated hepatic inflammation (Kim et al., 2019a). The combination of Ganmaidazao and Shengmai-Yin decoction is applied as adjuvant therapy for Type II diabetes mellitus via activation of HSL, PPAR $\alpha$, and AMPK/PI3K/AKT, and inhibition of SREBP-1/FAS, influencing insulin sensitivity, and lipid biosynthesis (Li et al., 2019). Two types of anti-dyslipidemia herb formulas (Fenofibrate and xuezhikang) have been simultaneously applied in the treatment of NAFLD (Hong et al., 2007) as well as combined use of Fructus Schisandrae with statin showed anti-oxidative effect and inhibitory effect against liver toxicity (Wat et al., 2016). Schisandra chinensis Baill has been used as a complementary therapy for rosiglitazone and alleviated NASH with significantly lower levels of LDLC and SOD in liver than rosiglitazone (Yao et al., 2014; Wat et al., 2016). Therefore, herbal medicine supplement combined with other therapeutic approaches 
TABLE 1 | The recent research for herb medicine in the setting of NAFLD therapy.

\begin{tabular}{|c|c|c|c|c|c|c|c|}
\hline \multirow[t]{2}{*}{ Herbal Medicine } & \multirow[t]{2}{*}{ Source organism } & \multirow[t]{2}{*}{ Pharmacological model } & \multirow{2}{*}{$\begin{array}{l}\text { Treatment } \\
\text { (Pharmacological } \\
\text { model and } \\
\text { Duration) }\end{array}$} & \multirow[t]{2}{*}{ Effective Dosage } & \multicolumn{3}{|c|}{ Reported mechanism of action } \\
\hline & & & & & Lipogenesis & $\begin{array}{l}\text { Modulation of } \\
\text { inflammatory } \\
\text { parameters }\end{array}$ & others \\
\hline S-allylmercaptocysteine & Garlic-derived & HFD induced obese rat & i.p, 3 times/week & $200 \mathrm{mg} / \mathrm{kg}$ & $\downarrow$ & $\downarrow N F-\kappa B$ and $A P-1$ & $\begin{array}{l}\downarrow \text { Collagen formation } \downarrow \text { Oxidative } \\
\text { stress } \uparrow \text { Autophagy }\end{array}$ \\
\hline \multirow{3}{*}{ Dioscin } & Polygonati Rhizoma & HFD induced obese rats & Orally, & 60 mg/kg & & $\downarrow \mid \kappa B \alpha, p 50$ and & $\downarrow$ Collagen formation \\
\hline & & $\begin{array}{l}\text { HFD induced obese Wistar rats and } \\
\text { mice }\end{array}$ & Orally, 8 weeks & $15-80 \mathrm{mg} / \mathrm{kg}$ & $\uparrow S I R T 1 / A M P K$ & p65 & $\downarrow$ Apoptosis \\
\hline & & $\begin{array}{l}\text { Dimethylnitrosamine-induced acute liver } \\
\text { injury mice }\end{array}$ & Orally, & $80 \mathrm{mg} / \mathrm{kg}$ & $\downarrow L X R \alpha$ & $\downarrow$ & $\downarrow$ Oxidative stress( $\uparrow S \mid R T 1, \mathrm{Nr} f 2)$ \\
\hline \multirow[t]{6}{*}{ Resveratrol } & & MCD diet induced NAFLD mice & Orally, & $\begin{array}{l}100 \text { or } 250 \mathrm{mg} / \mathrm{kg} / \\
\text { day }\end{array}$ & & $\downarrow$ TBARS & $\uparrow$ Autophagy \\
\hline & & AML12 cells & & $\begin{array}{l}25,50 \text {, or } 100 \mu \mathrm{mol} / \\
\mathrm{L}\end{array}$ & $\downarrow$ FFA uptake. & & \\
\hline & & $\begin{array}{l}\text { C57BL/6J mice and as ULK1+/- mice } \\
\text { with HFD }\end{array}$ & Orally, 4 weeks. & $50 \mathrm{mg} / \mathrm{kg}$ & & $\downarrow \mid \kappa B \alpha-N F-\kappa B$ & $\begin{array}{l}\downarrow \text { Oxidative stress } \\
\downarrow \text { Fibrosis }\end{array}$ \\
\hline & & Mice with HFD for 4 weeks & Orally, 4 weeks. & $0.40 \%$ & & & $\downarrow$ Oxidative stress \\
\hline & & HepG2 cells & $24 \mathrm{~h}$ & 20,40 , and $80 \mu \mathrm{M}$ & & & \\
\hline & & Wistar rats with HFD & Orally, 18 weeks & 200 mg/kg & & $\begin{array}{l}\uparrow \text { CAMP-PRKA- } \\
\text { AMPK-SIRT1 }\end{array}$ & $\downarrow$ ER stress( $\uparrow S I R T 1)$ \\
\hline Naringenin & Citrus-derived flavonoid & LDLR-/- mice with HFD & Orally, 4 weeks & $1 \%$ or $3 \% w t / w t$ & $\downarrow$ VLDL & & $\uparrow$ insulin resistance \\
\hline Yangonin & Piper methysticum & Mouse fed with HFD & Orally, 16 weeks & 10,20 , or $40 \mathrm{mg} / \mathrm{kg}$ & $\begin{array}{l}\text { \SREBP-1c } \\
\text { pathway; } \uparrow \text { fatty } \\
\text { acid } \beta \text {-oxidation }\end{array}$ & & $\begin{array}{l}\text { †insulin sensitivity } \\
\downarrow \text { Fibrosis }(\uparrow \text { FXR) }\end{array}$ \\
\hline \multirow[t]{3}{*}{ Berberine } & Coptidis Rhizoma & Mice fed with HFD & Orally; for 4 weeks & 300 mg/kg/day & $\begin{array}{l}\downarrow \text { SCD1 via } \\
\text { AMPK-SREBP- } \\
\text { 1c pathway }\end{array}$ & $\begin{array}{l}\text { p38MAPK/ERK- } \\
\text { COX2 pathways }\end{array}$ & $\downarrow$ Fibrosis \\
\hline & & AML12 & & $20 \mu \mathrm{M}$ & & & \\
\hline & & NASH-HCC mice model & Orally, 12 week & $250 \mathrm{mg} / \mathrm{kg}$ & & & \\
\hline \multirow[t]{3}{*}{ Betulinic acid } & Outer bark of tree species & Mice fed with HFD & Orally, 11 weeks & 50 mg/kg, & $\begin{array}{l}\downarrow \text { SREBP-1c, } \\
\text { ApoC2, RBP4, } \\
\text { FAS, and SCD- } \\
1 ; \uparrow A M P K \uparrow \\
\text { fatty acid } \\
\text { oxidation }\end{array}$ & $\begin{array}{l}\downarrow \mathrm{FF} 4 / 80, \mathrm{IL}-1 \alpha, \mathrm{IL}- \\
1 \beta, \mathrm{IL}-6, \mathrm{TNF}-\alpha\end{array}$ & $\downarrow$ Fibrosis ( $\uparrow$ FXR) \\
\hline & & AML12 treated with palmitic acid (PA) & & $50 \mu \mathrm{g} / \mathrm{ml}$ & & & \\
\hline & & Mice fed with MCD and HFD & Orally, 6 weeks & $100 \mathrm{mg} / 100 \mathrm{~g}$ diet & & & \\
\hline Glycyrrhizin & $\begin{array}{l}\text { Glycyrrhizae Radix Et } \\
\text { Rhizoma }\end{array}$ & Mice fed with MCD diet & i.p, 2 weeks & $50 \mathrm{mg} / \mathrm{kg}$ per day & $\downarrow$ lipogensis & $\begin{array}{l}\downarrow N L R P 3 \\
\uparrow F X R\end{array}$ & \\
\hline Gastrodin & Gastrodia elata BI & Larval zebrafish fed with HFD & & $10,25,50 \mathrm{mg} / \mathrm{L}$ & $\downarrow$ lipogensis & $\begin{array}{l}\downarrow T N F \alpha, \text { IL-6, and } \\
\text { IL1 } \beta\end{array}$ & $\begin{array}{l}\downarrow \text { Fibrosis } \downarrow T G F \beta 1 \text { ) } \\
\text { Oxidative stress } \uparrow N R F 2, \mathrm{HO}-1\end{array}$ \\
\hline Naringenin & Citrus-derived flavonoid & Ldlr-/- mice fed a Western diet & Orally, 4 weeks & 1 or $3 \%$ & $\begin{array}{l}\downarrow \text { SREBP1c; } \\
\text { \LLDL; fatty } \\
\text { acid oxidation }\end{array}$ & & $\downarrow$ hyperinsulinemia \\
\hline Puerarin & $\begin{array}{l}\text { Pueraria lobate (Willd.) } \\
\text { Ohwi }\end{array}$ & $\begin{array}{l}\text { Mice fed with a high-fat +high-sucrose } \\
\text { diet }\end{array}$ & Orally, 18 weeks & $0.2,0.4 \mathrm{~g} / \mathrm{kg} / \mathrm{day}$ & $\downarrow$ liver steatosis & $\downarrow$ & \Fibrosis $\downarrow$ TGF $\beta 1$ 1) \\
\hline
\end{tabular}




\begin{tabular}{|c|c|c|c|c|c|c|c|}
\hline \multirow[t]{2}{*}{ Herbal Medicine } & \multirow[t]{2}{*}{ Source organism } & \multirow[t]{2}{*}{ Pharmacological model } & \multirow{2}{*}{$\begin{array}{l}\text { Treatment } \\
\text { (Pharmacological } \\
\text { model and } \\
\text { Duration) }\end{array}$} & \multirow[t]{2}{*}{ Effective Dosage } & \multicolumn{3}{|c|}{ Reported mechanism of action } \\
\hline & & & & & Lipogenesis & $\begin{array}{l}\text { Modulation of } \\
\text { inflammatory } \\
\text { parameters }\end{array}$ & others \\
\hline \multirow[t]{3}{*}{ Silibinin } & $\begin{array}{l}\text { Silybum martanum (L.) } \\
\text { Gaertn. }\end{array}$ & MCD diet induced NASH mice & Orally, 6 weeks & $\begin{array}{l}10 \text { and } 20 \mathrm{mg} / \mathrm{kg} / \\
\text { day }\end{array}$ & $\uparrow \beta$-oxidation & $\begin{array}{l}\text { INASH via CFLAR- } \\
\text { JNK pathway, }\end{array}$ & $\begin{array}{l}\text { Oxidative stress } \uparrow C A T, \text { GSH-Px } \\
\text { and HO-1; } \downarrow \text { CYP2E } 1 \text {, CYP4A }\end{array}$ \\
\hline & & $\begin{array}{l}\text { NCTC- } 1469 \text { cells treated with OA plus } \\
\text { PA }\end{array}$ & & 50 and $100 \mu \mathrm{mol} / \mathrm{L}$ & & & \\
\hline & & HepG2 cells treated with OA & & $\begin{array}{l}5,20,50, \text { and } \\
100 \mu \mathrm{M}\end{array}$ & $\begin{array}{l}\text { \PPAR } \alpha \\
\text { SREBP-1C and } \\
\text { PNPLA3 }\end{array}$ & $\downarrow N O$ & 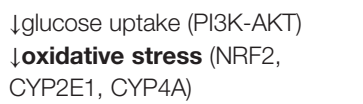 \\
\hline \multirow[t]{3}{*}{ Sparstolonin B } & $\begin{array}{l}\text { Sparganium stoloniferum } \\
\text { Buch-Ham }\end{array}$ & High-fat-fed mice & ip, for 4 week & $\begin{array}{l}3 \mathrm{mg} / \mathrm{kg} \text {, twice a } \\
\text { week }\end{array}$ & $\begin{array}{l}\downarrow T L R 4 \text { lipid raft } \\
\text { trafficking }\end{array}$ & $\downarrow$ TLR4 pathway & $\begin{array}{l}\downarrow \text { Fibrosis } \downarrow \text { TGF } \beta 1 \text { ) } \\
\downarrow N A D P H \text { oxidase activation. }\end{array}$ \\
\hline & & Kupffer cell line & & $100 \mu \mathrm{g} / \mathrm{ml}$ & & & \\
\hline & & LX2 cells with LPS (100 ng/ml) & & $10,100 \mu \mathrm{M}$ & & & \\
\hline Isochlorogenic acid B & Laggera alata (Asteraceae) & Mice fed with MCD diet & Orally, 4 weeks & 5,10 and $20 \mathrm{mg} / \mathrm{kg}$. & & & $\begin{array}{l}\downarrow \text { Fibrosis }(\downarrow T G F \beta 1, \text { LXO,MCP- } 1 \text {, } \\
\text { COL } 1 \alpha 1 \text { and TIMP- } 1 .) \\
\downarrow \text { oxidative stress ( } \uparrow N r f 2)\end{array}$ \\
\hline Swertiamarin & Swertia bimaculata & Fructose-fed mice for 12 week & Orally, 4 weeks & $\begin{array}{l}25,50 \text { and } 100 \mathrm{mg} / \\
\mathrm{kg}\end{array}$ & $\begin{array}{l}\downarrow \text { SREBP-1/ } \\
\text { FAS/ACC }\end{array}$ & $\begin{array}{l}\text { Jhepatic pro- } \\
\text { inflammation }\end{array}$ & $\begin{array}{l}\downarrow \text { hepatic xanthine oxidase }(\mathrm{XO}) \\
\uparrow N r f 2\end{array}$ \\
\hline Baicalin & $\begin{array}{l}\text { Scutellaria baicalensis } \\
\text { Georgi }\end{array}$ & MCD diet-induced NASH & Orally, 4weeks. & $\begin{array}{l}50 \text { and } 100,200 \mathrm{mg} / \\
\mathrm{kg}\end{array}$ & $\downarrow$ & $\downarrow$ inflammation & $\downarrow$ Fibrosis $\downarrow$ hepatic apoptosis. \\
\hline \multirow[t]{4}{*}{ Ursolic acid(UA) } & & Mice fed with HFD & Orally, 16 week & $0.05 \%(w / w) \cup A$ diet & & & $\downarrow$ Fibrosis \\
\hline & & T090-induced mouse model. & Orally, 7 days & $100,250 \mathrm{mg} / \mathrm{kg} /$ day & $\begin{array}{l}\text { Liver } X \text { Receptor } \\
\alpha \text { antagonist }\end{array}$ & & \\
\hline & & L02 cells treated with PA & & $10-30 \mu \mathrm{g} / \mathrm{ml}$ & $\begin{array}{l}\downarrow \text { lipid } \\
\text { accumulation }\end{array}$ & & \oxidative stress. \\
\hline & & Rat fed with HFD & Orally, 6 weeks. & $\begin{array}{l}0.125 \%, 0.25 \% \\
0.5 \% \text { UA diet }\end{array}$ & & $\downarrow$ inflammation & $\downarrow$ insulin resistance \\
\hline \multirow[t]{2}{*}{ Andrographolide } & $\begin{array}{l}\text { Andrographis paniculata } \\
\text { (Burm. f.)Nee }\end{array}$ & Mice fed with CDAA diet & i.p, 22 weeks & $\begin{array}{l}1 \mathrm{mg} / \mathrm{kg}, 3 \text { times/ } \\
\text { week }\end{array}$ & & $\begin{array}{l}\downarrow \text { hepatic } \\
\text { inflammation }\end{array}$ & $\downarrow$ collagen formation \\
\hline & & Fat-laden HepG2 cells. & & $50 \mu \mathrm{M}$ & & $\downarrow N F-\kappa B$ & \\
\hline \multirow[t]{2}{*}{ Ginsenoside Rb1 } & Panax Ginseng C.A.Mey & Rat fed with HFD & ip & $10 \mathrm{mg} / \mathrm{kg}$ & $\uparrow \mathrm{CPT} 1$ & & \\
\hline & & $\mathrm{db} / \mathrm{db}$ mice & i.p, 14 days. & 20 mg/kg & $\downarrow$ & $\downarrow$ & \\
\hline Nobiletin & Citrus reticulata Blanco & $\begin{array}{l}\text { Mice fed a high-fat diet } \\
\text { High glucose induced hepG2 cells }\end{array}$ & Orally, 16 weeks. & $\begin{array}{l}0.02 \%, \mathrm{w} / \mathrm{w} \\
5,25, \text { and } 50 \mu \mathrm{M}\end{array}$ & $\uparrow A M P K$ & $\downarrow N L R P 3$ & \\
\hline \multirow[t]{2}{*}{ Ginsenoside Rb2 } & Panax Ginseng C.A.Mey & HepG2 cells & & $50 \mu \mathrm{mol} / \mathrm{L}$ & & & $\uparrow$ Autophagy \\
\hline & & $\mathrm{db} / \mathrm{db}$ mice & i.p, 4 weeks & 10 mg/kg & $\begin{array}{l}\uparrow A M P K \text { or } \\
\text { SIRT1 }\end{array}$ & & \\
\hline \multirow[t]{2}{*}{ Akebia saponin D } & $\begin{array}{l}\text { Dipsacus asper Wall.ex } \\
\text { Henry }\end{array}$ & ob/ob mice fed with HFD & i.p, 4 weeks & $30,60,120$ mg/kg, & & & $\uparrow$ Autophagy \\
\hline & & OA stressed Buffalo rat liver cells & & 1,10 , and $100 \mu \mathrm{M}$ & & & $\uparrow$ LC3-II \P62 \\
\hline Glycycoumarin & Rhizoma Glycyrrhizae & $\begin{array}{l}\text { PA stressed cells (HepG2, AML-12, } \\
\text { and L02) }\end{array}$ & & $10-40 \mu \mathrm{M}$ & & & $\begin{array}{l}\downarrow \text { Mitochondrial apoptosis( } \downarrow \text { GSK- } \\
3, \downarrow \text { JNK) }\end{array}$ \\
\hline & & MCD diet induced NASH mice & i.p. 4 weeks & GCM 15 mg/kg/day & $\downarrow$ Lipogenesis & $\downarrow$ Inflammation & $\downarrow$ Fibrosis; Oxidative stress \\
\hline ethanol extract & $\begin{array}{l}\text { Lycopus lucidus Turcz. ex } \\
\text { Benth }\end{array}$ & HepG2 cells treated with OA plus PA & & $250-1000 \mathrm{mg} / \mathrm{ml}$ & $\begin{array}{l}\uparrow P P A R \alpha, \text { AMPK } \\
\downarrow \text { SREBP-1C }\end{array}$ & & \\
\hline
\end{tabular}




\begin{tabular}{|c|c|c|c|c|c|c|c|}
\hline \multirow[t]{2}{*}{ Herbal Medicine } & \multirow[t]{2}{*}{ Source organism } & \multirow[t]{2}{*}{ Pharmacological model } & \multirow{2}{*}{$\begin{array}{l}\text { Treatment } \\
\text { (Pharmacological } \\
\text { model and } \\
\text { Duration) }\end{array}$} & \multirow[t]{2}{*}{ Effective Dosage } & \multicolumn{3}{|c|}{ Reported mechanism of action } \\
\hline & & & & & Lipogenesis & $\begin{array}{l}\text { Modulation of } \\
\text { inflammatory } \\
\text { parameters }\end{array}$ & others \\
\hline & & Mice fed with HFD & Orally, 14 weeks. & $\begin{array}{l}100 \text { or } 200 \mathrm{mg} / \mathrm{kg} / \\
\text { day }\end{array}$ & & $\downarrow T N F-\alpha$ & \\
\hline $\begin{array}{l}\text { Danshen aqueous } \\
\text { extract }\end{array}$ & Salviae miltiorrhiza Bge. & Mice fed with ethanol & Orally, 9 days & $\begin{array}{l}0.093,0.28,0.84 \mathrm{~g} / \\
\mathrm{kg}\end{array}$ & $\downarrow$ Lipogenesis & $\downarrow$ Inflammation & $\downarrow$ Fibrosis \\
\hline \multirow[t]{2}{*}{ Jwa Kum Whan } & $\begin{array}{l}\text { Scutellariae Radix and } \\
\text { Euodiae Fructus }\end{array}$ & Mice fed with HFD & Orally, 15 week & 100,200 mg/kg daily & & & †Insulin Signaling \\
\hline & & HepG2 cells & & $\begin{array}{l}10,25,50,75, \text { or } \\
100 \mu \mathrm{g} / \mathrm{ml}\end{array}$ & & & \\
\hline \multirow[t]{2}{*}{ Ethanol Extract } & Leonurus japonicus Houtt. & Mice fed with HFD & Orally, 14 weeks & 100 or $200 \mathrm{mg} / \mathrm{kg}$ & $\begin{array}{l}\uparrow \text { AMPK, } \\
\operatorname{PPAR} \alpha\end{array}$ & & †Insulin Signaling \\
\hline & & $\begin{array}{l}1 \mathrm{mM} \text { free fatty acid induced HepG2 } \\
\text { cells }\end{array}$ & & $\begin{array}{l}250,500,750, \text { or } \\
1000 \mu \mathrm{g} / \mathrm{ml}\end{array}$ & $\begin{array}{l}\uparrow \mathrm{AMPK} \\
\operatorname{PPAR} \alpha\end{array}$ & & \\
\hline honeyberry extract & Lonicera caerulea & Mice fed with HFD & Orally, 6 weeks. & $0.5 \%, 1 \%$ & $\begin{array}{l}\uparrow \text { AMPK, CPT- } \\
1, \text { PPAR } \alpha\end{array}$ & & \\
\hline polysaccharides & Lycium barbarum L. & Rat treated with HFD & Orally, 4 weeks & $1 \mathrm{mg} / \mathrm{kg}$ & $\begin{array}{l}\downarrow \text { lipid } \\
\text { accumulation } \uparrow \\
\text { fatty acid } \\
\text { oxidation }\end{array}$ & & \\
\hline methanolic extract & $\begin{array}{l}\text { Alisma orientale (Sam.) } \\
\text { Juzep. }\end{array}$ & Rats fed with HFD for 6 weeks & Orally, 6 week & $\begin{array}{l}150,300 \text {, and } 600 \\
\mathrm{mg} / \mathrm{kg}\end{array}$ & $\uparrow A M P K$, PPAR $\alpha$ & $\downarrow$ Inflammation & $\begin{array}{l}\text { \apoptosis; } \downarrow \text { oxidative } \\
\text { stress; } \uparrow \text { insulin sensitive }\end{array}$ \\
\hline Seed Extract & Psoralea corylifolia L. & Mice fed a HFD & orally, 12 weeks & 300 or 500 mg/g/d, & $\downarrow$ Lipogenesis & $\downarrow$ Inflammation & †Insulin Signaling \\
\hline Extract & $\begin{array}{l}\text { Schisandra chinensis } \\
\text { (Turcz)Baill }\end{array}$ & Wister rats fed with HFD & 56 days & $100 \mathrm{mg} / \mathrm{kg} / \mathrm{day}$ & $\downarrow$ LDLC & & $\begin{array}{l}\downarrow \text { Endoplasmic reticulum (ER) } \\
\text { stress }\end{array}$ \\
\hline Total saponins & Aralia elata Seem. & ApoE-/- mouse fed with HFD. & i.g., 12 weeks. & $75,150 \mathrm{mg} / \mathrm{kg} /$ day & & $\downarrow$ Inflammation & \oxidative stress. \\
\hline Total alkaloids & Rubus aleaefolius Poir. & HFD for 8 weeks & orally, 4 weeks & $1.44,0.72 \mathrm{~g} / \mathrm{kg}$ & $\begin{array}{l}\downarrow F A S, A C C \\
\uparrow C P T\end{array}$ & & \\
\hline $\begin{array}{l}\text { Polygonatum } \\
\text { kingianum }\end{array}$ & & Rat fed with HFD & Orally, 14 weeks & $1,2,4 \mathrm{~g} / \mathrm{kg}$ & & & $\begin{array}{l}\text { Remedy mitochondrial } \\
\text { dysfunction }\end{array}$ \\
\hline Ethyl acetate extract & $\begin{array}{l}\text { Aristolochia manshuriensis } \\
\text { Kom }\end{array}$ & HFD-induced NASH model & 15 weeks & $2.5 \mathrm{mg} / \mathrm{kg}$ & & $\downarrow$ Inflammation & 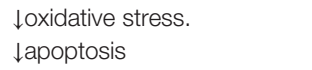 \\
\hline Fructus Schisandrae & & SD rats fed with HFD for 8 weeks: & orally, 8 weeks & $\begin{array}{l}0.45 \% \mathrm{FS}+0.3 \% \\
\text { Atorvastatin }\end{array}$ & & & $\downarrow$ oxidative stress. \\
\hline Aqueous extract & Salvia miltiorrhiza Bunge & $\begin{array}{l}\text { Ovariectomized }(\mathrm{OVX})+\text { hyperlipidemic } \\
\text { SD rats }\end{array}$ & Orally, 12 weeks & $600 \mathrm{mg} / \mathrm{kg} / \mathrm{d}$ & & & $\downarrow$ Fibrosis \\
\hline The chloroform extract & Cyclocarya paliurus & SD rats fed with HFD for 6 weeks & Orally, 4 weeks. & & & & $\downarrow$ Fibrosis \\
\hline $\begin{array}{l}\text { Saponins Raw and } \\
\text { processed }\end{array}$ & $\begin{array}{l}\text { Panax Notoginseng (Burk.) } \\
\text { F.H.Chen }\end{array}$ & $\mathrm{CCl}_{4}$ induced fibrosis in rat & i.p & $130 \mathrm{mg} / \mathrm{kg}$ & & $\downarrow$ Inflammation & $\downarrow$ Fibrosis \\
\hline $\begin{array}{l}\text { Citrus aurantium Peel } \\
\text { Extract }\end{array}$ & $\begin{array}{l}\text { Citrus aurantium L. } \\
\text { (Rutaceae) }\end{array}$ & Mice fed with HFD & orally, 8 weeks & $50,100 \mathrm{mg} / \mathrm{kg}$ & $\begin{array}{l}\downarrow \text { PPAR }-\gamma \\
\text { SREBP- }-1 \mathrm{c}\end{array}$ & $\downarrow$ inflammation & \\
\hline \multirow{3}{*}{$\begin{array}{l}\text { Korea red ginseng } \\
\text { Celastrus orbiculatus } \\
\text { Thunb. }\end{array}$} & Panax ginseng C.A.Mey & Fatty Rats & orally, 2 months & 200 mg/kg/day & & $\downarrow$ inflammation & $\downarrow$ oxidative stress. \\
\hline & & ApoE(-/-) mice & Orally, 6 weeks & $10.0 \mathrm{~g} / \mathrm{kg} / \mathrm{d}$ & †adiponectin & $\begin{array}{l}\downarrow T L R 4 \text { and NF-kB } \\
\text { p65, TNF- } \alpha .\end{array}$ & \\
\hline & & A guinea pig of NAFLD & Orally, 8 weeks & & $\begin{array}{l}\uparrow \text { CYP7A1 and } \\
\text { HMGCR }\end{array}$ & & $\downarrow N O$ and iNOS levels \\
\hline
\end{tabular}


Herbal Medicine

Source organism

Pharmacological model

\section{Treatment \\ (Pharmacological \\ model and}

Duration)

Effective Dosage

Reported mechanism of action

Lipogenesis $\quad \begin{aligned} & \text { Modulation of } \\ & \text { inflammatory }\end{aligned}$

Lipogenesis $\begin{aligned} & \text { Modulation of } \\ & \text { inflammatory }\end{aligned}$

parameters

Notoginseng Radix Et

Rhizoma

Lingguizhugan

decoction

Poria, Ramulus

Cinnamomi, Atractylodis

Macrocephalae Rhizom

Glycyrrhizae Radix Et

Rhizoma

Tangshen formula Puerariae Radix,

Astragalus, Ligustrum

lucidum Ait, Ganoderma,

Salvia miltiorrhizae Radix

Et Rhizoma, Rhei Radix Et

Rhizoma

Fenofibrate and

Xuezhikang

Bangpungtongseong- Talcum, Glycyrrhiza

san
Scutellaria baicalensis,

Platycodon grandiflorum,

Ledebouriella seseloides,

Cnidium officinale,

Angelica gigas,Paeonia

lactiflora,Rheum

undulatum, Ephedra

sinica, Mentha pulegium

Forsythia koreana,

Erigeron canadensis,

Schizonepeta tenuifolia,

Atractylodes japonica,

Gardenia jasminoides,

Zingiber officinale

\section{HepG2 cells}

Rat fed with HFD

HFD induced obese mice
$90 \mathrm{mg} / \mathrm{kg}$,

combination with

calorie restriction

Fecal microbiota

transplantation

Orally, 16 weeks $\quad 2.4 \mathrm{~g} / \mathrm{kg} /$ day $\quad \uparrow A M P K / S I R T 1$

$25,50,100 \mu \mathrm{g} / \mathrm{ml}$

Orally, 6 weeks $\quad F(100 \mathrm{mg} / \mathrm{kg})$ and $X \quad \uparrow P P A R \alpha \quad \downarrow T N F-\alpha$.

(300 mg/kg)

12 weeks $\quad 1.5 \% \mathrm{w} / \mathrm{w} \quad \uparrow$ mitochondrial

antioxidant 


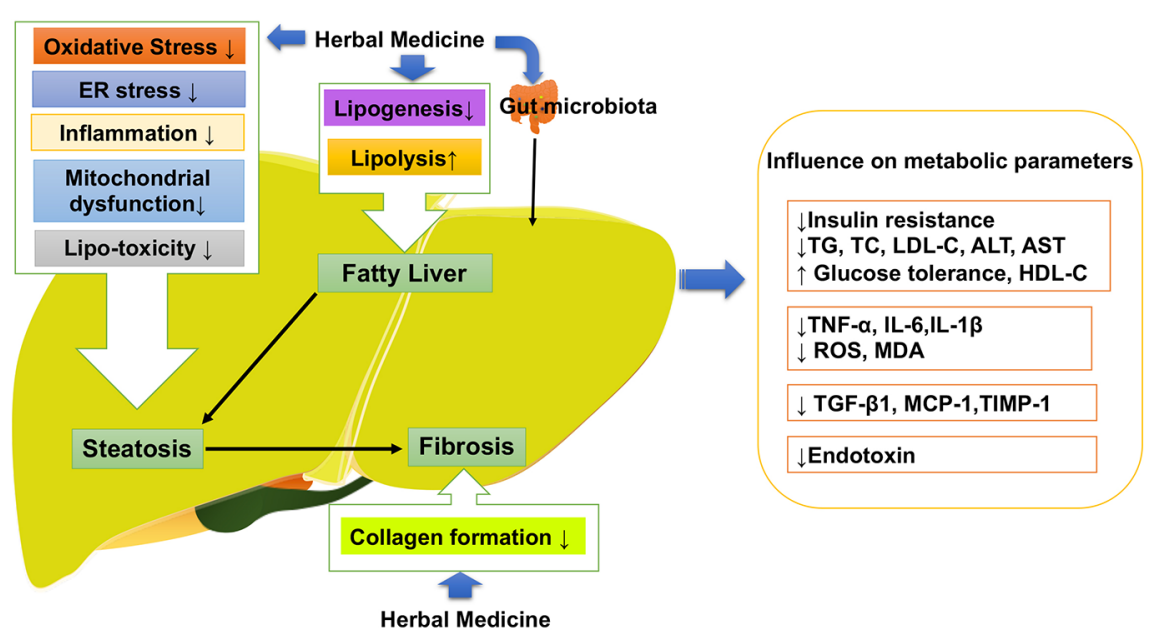

FIGURE 3 | Herbal medicine mediated the key pathological events in the procession of NAFLD. NAFLD, Non-alcoholic fatty liver disease.

might provide feasible therapeutic strategies for patients with NAFLD (Porras et al., 2018).

\section{AUTHOR CONTRIBUTIONS}

YF and designed and conceived the study. YX, NW, and YF retrieved, analyzed the data and drafted the manuscript. WG, CZ, FC, HT, SL, and NW discussed and revised the manuscript. All authors confirmed final version of the manuscript.

\section{REFERENCES}

Aguirre, L., Fernández-Quintela, A., Arias, N., and Portillo, M. P. (2014). Resveratrol: anti-obesity mechanisms of action. Molecules (Basel, Switzerland). 19, 18632-18655. doi: 10.3390/molecules 191118632

Ahmad, O., Wang, B., Ma, K., Deng, Y., Li, M., Yang, L., et al. (2019). Lipid Modulating Anti-oxidant Stress Activity of Gastrodin on Nonalcoholic Fatty Liver Disease Larval Zebrafish Model. Int. J. Mol. Sci. 20, 1984. doi: 10.3390/ ijms20081984

Arase, Y., Shiraishi, K., Anzai, K., Sato, H., Teramura, E., Tsuruya, K., et al. (2019). Effect of Sodium Glucose Co-Transporter 2 Inhibitors on Liver Fat Mass and Body Composition in Patients with Nonalcoholic Fatty Liver Disease and Type 2 Diabetes Mellitus. Clin. Drug Invest. 39, 631-641. doi: 10.1007/s40261-01900785-6

Askari, F., Rashidkhani, B., and Hekmatdoost, A. (2014). Cinnamon may have therapeutic benefits on lipid profile, liver enzymes, insulin resistance, and highsensitivity C-reactive protein in nonalcoholic fatty liver disease patients. Nutr. Res. 34, 143-148. doi: 10.1016/j.nutres.2013.11.005

Bai, L., and Li, H. (2019). Innate immune regulatory networks in hepatic lipid metabolism. J. Mol. Med. (Berl) 97, 593-604. doi: 10.1007/s00109-019-01765-1

Berman, A. Y., Motechin, R. A., Wiesenfeld, M. Y., and Holz, M. K. (2017). The therapeutic potential of resveratrol: a review of clinical trials. NPJ Precis. Oncol. 1, 35. doi: 10.1038/s41698-017-0038-6

Bertot, L. C., and Adams, L. A. (2019). Trends in hepatocellular carcinoma due to non-alcoholic fatty liver disease. Expert Rev. Gastroenterol. Hepatol. 13, 179187. doi: 10.1080/17474124.2019.1549989

\section{FUNDING}

This research was partially supported by the Research Council of the University of Hong Kong (project codes: 104004092 and 104004460), Wong's donation (project code: 200006276), a donation from the Gaia Family Trust of New Zealand (project code: 200007008), the Research Grants Committee (RGC) of Hong Kong, HKSAR (Project Codes: 740608, 766211, 17152116, and 17121419), Health and Medical Research Fund (Project code: 15162961, 16171511, and 16172751).

Blevins, S. M., Leyva, M. J., Brown, J., Wright, J., Scofield, R. H., and Aston, C. E. (2007). Effect of cinnamon on glucose and lipid levels in non insulin-dependent type 2 diabetes. Diabetes Care 30, 2236-2237. doi: 10.2337/dc07-0098

Brunner, K. T., Henneberg, C. J., Wilechansky, R. M., and Long, M. T. (2019). Nonalcoholic Fatty Liver Disease and Obesity Treatment. Curr. Obes. Rep. 8, 220-228. doi: 10.1007/s13679-019-00345-1

Cabrera, D., Wree, A., Povero, D., Solis, N., Hernandez, A., Pizarro, M., et al. (2017). Andrographolide Ameliorates Inflammation and Fibrogenesis and Attenuates Inflammasome Activation in Experimental Non-Alcoholic Steatohepatitis. Sci. Rep. 7, 3491. doi: 10.1038/s41598-017-03675-Z

Cai, Y., Liang, Q., Chen, W., Chen, M., Chen, R., Zhang, Y., et al. (2019). Evaluation of HuoXueHuaYu therapy for nonalcoholic fatty liver disease: a systematic review and meta-analysis of randomized controlled trial. BMC Complement. Altern. Med. 19, 178. doi: 10.1186/s12906-019-2596-3

Cao, G.-S., Li, S.-X., Wang, Y., Xu, Y.-Q., Lv, Y.-N., Kou, J.-P., et al. (2016). A combination of four effective components derived from Sheng-mai san attenuates hydrogen peroxide-induced injury in PC12 cells through inhibiting Akt and MAPK signaling pathways. Chin. J. Natural Medicines 14, 508-517. doi: 10.1016/S1875-5364(16)30060-7

Cheng, S., Liang, S., Liu, Q., Deng, Z., Zhang, Y., Du, J., et al. (2018). Diosgenin prevents high-fat diet-induced rat non-alcoholic fatty liver disease through the AMPK and LXR signaling pathways. Int. J. Mol. Med. 41, 1089-1095. doi: $10.3892 / \mathrm{ijmm}$

Cheng, K., Song, Z., Zhang, H., Li, S., Wang, C., Zhang, L., et al. (2019). The therapeutic effects of resveratrol on hepatic steatosis in high-fat diet-induced obese mice by improving oxidative stress, inflammation and lipid-related gene 
transcriptional expression. Med. Mol. Morphol. 52, 187-197. doi: 10.1007/ s00795-019-00216-7

Choi, E., Jang, E., and Lee, J. H. (2019). Pharmacological Activities of Alisma orientale against Nonalcoholic Fatty Liver Disease and Metabolic Syndrome: Literature Review. Evid. Based. Complement. Alternat. Med. 2019, 2943162. doi: $10.1155 / 2019 / 2943162$

Choi, J. Y., Kwon, E. Y., and Choi, M. S. (2019). Elucidation of the Metabolic and Transcriptional Responses of an Oriental Herbal Medicine, Bangpungtongseongsan, to Nonalcoholic Fatty Liver Disease in Diet-Induced Obese Mice. J. Med. Food. doi: 10.1089/jmf.2018.4383

Clapper, J. R., Hendricks, M. D., Gu, G., Wittmer, C., Dolman, C. S., Herich, J., et al. (2013). Diet-induced mouse model of fatty liver disease and nonalcoholic steatohepatitis reflecting clinical disease progression and methods of assessment. Am. J. Physiol. Gastrointest. Liver Physiol. 305, G483-G495. doi: 10.1152/ajpgi.00079.2013

Dattaroy, D., Seth, R. K., Das, S., Alhasson, F., Chandrashekaran, V., Michelotti, G., et al. (2016). Sophocarpine alleviates hepatocyte steatosis through activating AMPK signaling pathway. Am. J. Physiol. Gastrointest. Liver Physiol. 310, G510-G525. doi: 10.1016/j.tiv

Dattaroy, D., Seth, R. K., Sarkar, S., Kimono, D., Albadrani, M., Chandrashekaran, V., et al. (2018). Sparstolonin B (SsnB) attenuates liver fibrosis via a parallel conjugate pathway involving P53-P21 axis, TGF-beta signaling and focal adhesion that is TLR4 dependent. Eur. J. Pharmacol. 841, 33-48. doi: 10.1016/ j.ejphar.2018.08.040

Ding, S., Jiang, J., Zhang, G., Bu, Y., Zhang, G., and Zhao, X. (2017). Resveratrol and caloric restriction prevent hepatic steatosis by regulating SIRT1-autophagy pathway and alleviating endoplasmic reticulum stress in high-fat diet-fed rats. PloS One 12, e0183541. doi: 10.1371/journal.pone.0183541

Ding, J., Zhang, B., Wang, P. J., He, G. N., Wei, D. M., Ding, J. L., et al. (2019). Analysis on mechanisms and medication rules of herbal prescriptions for nonalcoholic fatty liver disease based on methods of data mining and biological information. Zhongguo Zhong Yao Za Zhi 44, 1689-1695. doi: 10.19540/ j.cnki.cjcmm

Dong, R., Yang, X., Wang, C., Liu, K., Liu, Z., Ma, X., et al. (2019). Yangonin protects against non-alcoholic fatty liver disease through farnesoid $\mathrm{X}$ receptor. Phytomedicine 53, 134-142. doi: 10.1016/j.phymed.2018.09.006

Fan, J.-G. (2004). Evaluating the efficacy and safety of Danning Pian in the shortterm treatment of patients with non-alcoholic fatty liver disease: a multicenter clinical trial. Hepatobiliary Pancreatic Dis. Int. 3, 375-380.

Fang, K., Wu, F., Chen, G., Dong, H., Li, J., Zhao, Y., et al. (2019). Diosgenin ameliorates palmitic acid-induced lipid accumulation via AMPK/ACC/CPT$1 \mathrm{~A}$ and SREBP-1c/FAS signaling pathways in LO2 cells. BMC Complement Altern. Med. 19, 255. doi: 10.1186/s12906-019-2671-9

Feng, Q., Gou, X. J., Meng, S. X., Huang, C., Zhang, Y. Q., Tang, Y. J., et al. (2013). Qushi Huayu Decoction Inhibits Hepatic Lipid Accumulation by Activating AMP-Activated Protein Kinase In Vivo and In Vitro. Evid. Based. Complement. Alternat. Med. 2013, 184358. doi: 10.1155/2013/184358

Feng, Y., Chen, Y., Yang, B., Lan, Q., Wang, T., Cui, G., et al. (2019). Hepatoprotective Effect of Jianpi Huoxue Formula on Nonalcoholic Fatty Liver Disease Induced by Methionine-Choline-Deficient Diet in Rat. BioMed. Res. Int. 2019, 7465272. doi: 10.1155/2019/7465272

Gao, B. Z., Chen, J. C., Liao, L. H., Xu, J. Q., Lin, X. F., and Ding, S. S. (2015). Erchen Decoction Prevents High-Fat Diet Induced Metabolic Disorders in C57BL/6 Mice. Evid. Based. Complement. Alternat. Med. 2015, 501272. doi: $10.1155 / 2015 / 501272$

German, M. N., Lutz, M. K., Pickhardt, P. J., Bruce, R. J., and Said, A. (2019). Statin Use is Protective Against Hepatocellular Carcinoma in Patients With Nonalcoholic Fatty Liver Disease: A Case-control Study. J. Clin. Gastroenterol. 8, 876. doi: 10.1097/MCG.0000000000001260

Gong, L. L., Li, G. R., Zhang, W., Liu, H., Lv, Y. L., Han, F. F., et al. (2016). Akebia Saponin D Decreases Hepatic Steatosis through Autophagy Modulation. J. Pharmacol. Exp. Ther. 359, 392-400. doi: 10.1124/jpet.116.236562

Gu, M., Zhao, P., Zhang, S., Fan, S., Yang, L., Tong, Q., et al. (2019). Betulinic acid alleviates endoplasmic reticulum stress-mediated nonalcoholic fatty liver disease through activation of farnesoid $\mathrm{X}$ receptors in mice. Br. J. Pharmacol. 176, 847-863. doi: 10.1111/bph.14570

Han, H. Y., Lee, S. K., Choi, B. K., Lee, D. R., Lee, H. J., and Kim, T. W. (2019). Preventive Effect of Citrus aurantium Peel Extract on High-Fat Diet-Induced
Non-alcoholic Fatty Liver in Mice. Biol. Pharm. Bull. 42, 255-260. doi: 10.1248/ bpb.b18-00702

Heinrich, M., Appendino, G., Efferth, T., Fürst, R., Izzo, A. A., Kayser, O., et al. (2020). Best practice in research - Overcoming common challenges in phytopharmacological research. J. Ethnopharmacol. 246, 112230. doi: 10.1016/j.jep.2019.112230

Hong, X., Tang, H., Wu, L., and Li, L. (2006). Protective effects of the Alisma orientalis extract on the experimental nonalcoholic fatty liver disease. J. Pharm. Pharmacol. 58, 1391-1398. doi: 10.1211/jpp.57.10.0013

Hong, X. Z., Li, L. D., and Wu, L. M. (2007). Effects of fenofibrate and xuezhikang on high-fat diet-induced non-alcoholic fatty liver disease. Clin. Exp. Pharmacol. Physiol. 34, 27-35. doi: 10.1111/j.1440-1681.2007.04547.x

Hong, S. H., Suk, K. T., Choi, S. H., Lee, J. W., Sung, H. T., Kim, C. H., et al. (2013). Anti-oxidant and natural killer cell activity of Korean red ginseng (Panax ginseng) and urushiol (Rhus vernicifera Stokes) on non-alcoholic fatty liver disease of rat. Food Chem. Toxicol. 55, 586-591. doi: 10.1016/j.fct.2013.01.022

Hong, M., Lee, Y. H., Kim, S., Suk, K. T., Bang, C. S., Yoon, J. H., et al. (2016). Antiinflammatory and antifatigue effect of Korean Red Ginseng in patients with nonalcoholic fatty liver disease. J. Ginseng Res. 40, 203-210. doi: 10.1016/ j.jgr.2015.07.006

Hong, M., Li, S., Wang, N., Tan, H. Y., Cheung, F., and Feng, Y. (2017). A Biomedical Investigation of the Hepatoprotective Effect of Radix salviae miltiorrhizae and Network Pharmacology-Based Prediction of the Active Compounds and Molecular Targets. Int. J. Mol. Sci. 18, 620. doi: 10.3390/ ijms 18030620

Hormati, A., Tooiserkany, F., Mohammadbeigi, A., Aliasl, F., and Dehnavi, H. M. (2019). Effect of an Herbal Product on the Serum Level of Liver Enzymes in Patients with Non-Alcoholic Fatty Liver Disease: A Randomized, DoubleBlinded, Placebo-Controlled Trial. Iran. Red Crescent Med. J. 21, 7. doi: 10.5812 /ircmj. 91024

Hu, R., Yan, H., Hao, X., Liu, H., and Wu, J. (2013). Shizukaol D isolated from Chloranthus japonicas inhibits AMPK-dependent lipid content in hepatic cells by inducing mitochondrial dysfunction. PloS One 8, e73527. doi: 10.1371/ journal.pone.0073527

Huang, M. Q., Zhou, C. J., Zhang, Y. P., Zhang, X. Q., Xu, W., Lin, J., et al. (2016). Salvianolic Acid B Ameliorates Hyperglycemia and Dyslipidemia in $\mathrm{db} / \mathrm{db}$ Mice through the AMPK Pathway. Cell Physiol. Biochem. 40, 933-943. doi: $10.1159 / 000453151$

Huang, Q., Wang, T., Yang, L., and Wang, H. Y. (2017). Ginsenoside Rb2 Alleviates Hepatic Lipid Accumulation by Restoring Autophagy via Induction of Sirt1 and Activation of AMPK. Int. J. Mol. Sci. 18, 1063. doi: 10.3390/ijms18051063

Ji, G., Wang, Y., Deng, Y., Li, X., and Jiang, Z. (2015). Resveratrol ameliorates hepatic steatosis and inflammation in methionine/choline-deficient dietinduced steatohepatitis through regulating autophagy. Lipids Health Dis. 14, 134. doi: 10.1186/s12944-015-0139-6

Ji, X., Shi, S., Liu, B., Shan, M., Tang, D., Zhang, W., et al. (2019). Bioactive compounds from herbal medicines to manage dyslipidemia. BioMed. Pharmacother. 118, 109338. doi: 10.1016/j.biopha.2019.109338

Jiang, Y., Chen, L., Wang, H., Narisi, B., and Chen, B. (2015). Li-Gan-Shi-Liu-BaWei-San improves non-alcoholic fatty liver disease through enhancing lipid oxidation and alleviating oxidation stress. J. Ethnopharmacol. 176, 499-507. doi: 10.1016/j.jep.2015.11.019

Kim, Y. J., Choi, M. S., Woo, J. T., Jeong, M. J., Kim, S. R., and Jung, U. J. (2017). Long-term dietary supplementation with low-dose nobiletin ameliorates hepatic steatosis, insulin resistance, and inflammation without altering fat mass in dietinduced obesity. Mol. Nutr. Food Res. 61, 1600889. doi: 10.1002/mnfr.201600889

Kim, J. C., Jeon, J. Y., Yang, W. S., Kim, C. H., and Eom, D. W. (2019a). Combined Amelioration of Ginsenoside (Rg1, Rb1, and Rg3)-enriched Korean Red Ginseng and Probiotic Lactobacillus on Non-alcoholic Fatty Liver Disease. Curr. Pharm. Biotechnol. 20, 222-231. doi: 10.2174/1389201020666190311143554

Kim, K. D., Jung, H. Y., Ryu, H. G., Kim, B., Jeon, J., Yoo, H. Y., et al. (2019b). Betulinic acid inhibits high-fat diet-induced obesity and improves energy balance by activating AMPK. Nutr. Metab. Cardiovasc. Dis. 29, 409-420. doi: 10.1016/j.numecd.2018.12.001

Kobayashi, S., Kawasaki, Y., Takahashi, T., Maeno, H., and Nomura, M. (2017). Mechanisms for the anti-obesity actions of bofutsushosan in high-fat diet-fed obese mice. Chin. Med. 12, 8. doi: 10.1186/s13020-017-0129-x 
Kwak, D. H., Kim, J. S., Chang, K. T., and Choo, Y. K. (2016). Aristolochia manshuriensis Kom ethyl acetate extract protects against high-fat diet-induced non-alcoholic steatohepatitis by regulating kinase phosphorylation in mouse. J. Vet Sci. 17, 279-287. doi: 10.4142/jvs.2016.17.3.279

Kwon, E. Y., Shin, S. K., and Choi, M. S. (2018). Ursolic Acid Attenuates Hepatic Steatosis, Fibrosis, and Insulin Resistance by Modulating the Circadian Rhythm Pathway in Diet-Induced Obese Mice. Nutrients 10, 1719. doi: $10.3390 /$ nu10111719

Lee, M. R., Park, K. I., and Ma, J. Y. (2017). Leonurus japonicus Houtt Attenuates Nonalcoholic Fatty Liver Disease in Free Fatty Acid-Induced HepG2 Cells and Mice Fed a High-Fat Diet. Nutrients 10, 20. doi: 10.3390/nu10010020

Lee, M. R., Yang, H. J., Park, K. I., and Ma, J. Y. (2019). Lycopus lucidus Turcz. ex Benth. Attenuates free fatty acid-induced steatosis in HepG2 cells and nonalcoholic fatty liver disease in high-fat diet-induced obese mice. Phytomedicine 55, 14-22. doi: 10.1016/j.phymed.2018.07.008

Li, S., Liao, X., Meng, F., Wang, Y., Sun, Z., Guo, F., et al. (2014a). Therapeutic role of ursolic acid on ameliorating hepatic steatosis and improving metabolic disorders in high-fat diet-induced non-alcoholic fatty liver disease rats. PloS One 9, e86724. doi: 10.1371/journal.pone.0086724

Li, Y., Zhao, J., Zheng, H., Zhong, X., Zhou, J., and Hong, Z. (2014b). Treatment of Nonalcoholic Fatty Liver Disease with Total Alkaloids in Rubus aleaefolius Poir through Regulation of Fat Metabolism. Evid. Based. Complement. Alternat Med. 2014, 768540. doi: 10.1155/2014/768540

Li, H., Ying, H., Hu, A., Hu, Y., and Li, D. (2017a). Therapeutic Effect of Gypenosides on Nonalcoholic Steatohepatitis via Regulating Hepatic Lipogenesis and Fatty Acid Oxidation. Biol. Pharm. Bull. 40, 650-657. doi: 10.1248/bpb.b16-00942

Li, W. S., Wu, Y., Ge, W. Z., Fan, L., and Sun, W. (2017b). A herbal formula Erchen decoction for non-alcoholic fatty liver disease: a systematic review and metaanalysis of randomized controlled trials. Int. J. Clin. Exp. Med. 10, 9110-9116.

Li, Y., Liu, T., Yan, C., Xie, R., Guo, Z., Wang, S., et al. (2018). Diammonium Glycyrrhizinate Protects against Nonalcoholic Fatty Liver Disease in Mice through Modulation of Gut Microbiota and Restoration of Intestinal Barrier. Mol. Pharm. 15, 3860-3870. doi: 10.1021/acs.molpharmaceut.8b00347

Li, S., Qian, Y., Xie, R., Li, Y., Jia, Z., Zhang, Z., et al. (2019). Exploring the protective effect of ShengMai-Yin and Ganmaidazao decoction combination against type 2 diabetes mellitus with nonalcoholic fatty liver disease by network pharmacology and validation in KKAy mice. J. Ethnopharmacol. 242, 112029. doi: 10.1016/j.jep.2019.112029

Lim, D. W., Kim, H., Lee, S. J., Yu, G. R., Kim, J. E., and Park, W. H. (2019). Jwa Kum Whan Attenuates Nonalcoholic Fatty Liver Disease by Modulating Glucose Metabolism and the Insulin Signaling Pathway. Evid. Based. Complement. Alternat. Med. 2019, 4589810. doi: 10.1155/2019/4589810

Lin, Z., Wu, Z. F., Jiang, C. H., Zhang, Q. W., Ouyang, S., Che, C. T., et al. (2016). The chloroform extract of Cyclocarya paliurus attenuates high-fat diet induced non-alcoholic hepatic steatosis in Sprague Dawley rats. Phytomedicine 23, 1475-1483. doi: 10.1016/j.phymed.2016.08.003

Lin, Y. N., Wang, C. C. N., Chang, H. Y., Chu, F. Y., Hsu, Y. A., Cheng, W. K., et al. (2018). Ursolic Acid, a Novel Liver X Receptor alpha (LXRalpha) Antagonist Inhibiting Ligand-Induced Nonalcoholic Fatty Liver and Drug-Induced Lipogenesis. J. Agric. Food Chem. 66, 11647-11662. doi: 10.1021/ acs.jafc.8b04116

Liou, C. J., Lee, Y. K., Ting, N. C., Chen, Y. L., Shen, S. C., Wu, S. J., et al. (2019). Protective Effects of Licochalcone A Ameliorates Obesity and Non-Alcoholic Fatty Liver Disease Via Promotion of the Sirt-1/AMPK Pathway in Mice Fed a High-Fat Diet. Cells 8, 447. doi: 10.3390/cells8050447

Liu, Z. L., Xie, L. Z., Zhu, J., Li, G. Q., Grant, S. J., and Liu, J. P. (2013). Herbal medicines for fatty liver diseases. Cochrane Database Syst. Rev. 8, CD009059. doi: 10.1002/14651858.CD009059.pub2

Liu, H.-K., Hung, T.-M., Huang, H.-C., Lee, I. J., Chang, C.-C., Cheng, J.-J., et al. (2015a). Bai-Hu-Jia-Ren-Shen-Tang Decoction Reduces Fatty Liver by Activating AMP-Activated Protein Kinase In Vitro and In Vivo. Evid. Based. Complement. Altern. Med. 2015, 651734. doi: 10.1155/2015/651734

Liu, M., Xu, L., Yin, L., Qi, Y., Xu, Y., Han, X., et al. (2015b). Potent effects of dioscin against obesity in mice. Sci. Rep. 5, 7973. doi: 10.1038/srep07973

Liu, Y., Yu, Q., and Chen, Y. (2018). Effect of silibinin on CFLAR-JNK pathway in oleic acid-treated HepG2 cells. Biomed. Pharmacother. 108, 716-723. doi: 10.1016/j.biopha.2018.09.089
Liu, K., Luo, M., and Wei, S. (2019a). The Bioprotective Effects of Polyphenols on Metabolic Syndrome against Oxidative Stress: Evidences and Perspectives. Oxid. Med. Cell. Longevity 2019, 1-16. doi: 10.1155/2019/6713194

Liu, M. T., Huang, Y. J., Zhang, T. Y., Tan, L. B., Lu, X. F., and Qin, J. (2019b). Lingguizhugan decoction attenuates diet-induced obesity and hepatosteatosis via gut microbiota. World J. Gastroenterol. 25, 3590-3606. doi: 10.3748/ wjg.v25.i27.3590

Liu, X., Huang, K., Niu, Z., Mei, D., and Zhang, B. (2019c). Protective effect of isochlorogenic acid B on liver fibrosis in non-alcoholic steatohepatitis of mice. Basic Clin. Pharmacol. Toxicol. 124, 144-153. doi: 10.1111/bcpt.13122

Liu, Y., Xu, W., Zhai, T., You, J., and Chen, Y. (2019d). Silibinin ameliorates hepatic lipid accumulation and oxidative stress in mice with non-alcoholic steatohepatitis by regulating CFLAR-JNK pathway. Acta Pharm. Sin. B 9, 745757. doi: 10.1016/j.apsb.2019.02.006

Loguercio, C., Andreone, P., Brisc, C., Brisc, M. C., Bugianesi, E., Chiaramonte, M., et al. (2012). Silybin combined with phosphatidylcholine and vitamin E in patients with nonalcoholic fatty liver disease: a randomized controlled trial. Free Radical Biol. Med. 52, 1658-1665. doi: 10.1016/j.freeradbiomed. 2012.02.008

Luo, Y., Dong, X., Yu, Y., Sun, G., and Sun, X. (2015). Total aralosides of aralia elata (Miq) seem (TASAES) ameliorate nonalcoholic steatohepatitis by modulating IRE1alpha-mediated JNK and NF-kappaB pathways in ApoE-/mice. J. Ethnopharmacol. 163, 241-250. doi: 10.1016/j.jep.2015.01.017

Luo, Y., Tian, G., Zhuang, Z., Chen, J., You, N., Zhuo, L., et al. (2019). Berberine prevents non-alcoholic steatohepatitis-derived hepatocellular carcinoma by inhibiting inflammation and angiogenesis in mice. Am. J. Transl. Res. 11, 26682682.

Marra, F., and Lotersztajn, S. (2013). Pathophysiology of NASH: perspectives for a targeted treatment. Curr. Pharm. Des. 19, 5250-5269. doi: 10.2174/ 13816128113199990344

Mouzaki, M., Comelli, E. M., Arendt, B. M., Bonengel, J., Fung, S. K., Fischer, S. E., et al. (2013). Intestinal microbiota in patients with nonalcoholic fatty liver disease. Hepatology 58, 120-127. doi: 10.1002/hep.26319

Mulvihill, E. E., Allister, E. M., Sutherland, B. G., Telford, D. E., Sawyez, C. G., Edwards, J. Y., et al. (2009). Naringenin Prevents Dyslipidemia, Apolipoprotein B Overproduction, and Hyperinsulinemia in LDL Receptor-Null Mice With Diet-Induced Insulin Resistance. Diabetes 58, 2198-2210. doi: 10.2337/db090634

Panahi, Y., Kianpour, P., Mohtashami, R., Jafari, R., Simental-Mendía, L. E., and Sahebkar, A. (2017). Efficacy and Safety of Phytosomal Curcumin in NonAlcoholic Fatty Liver Disease: A Randomized Controlled Trial. Drug Res. 67, 244-251. doi: 10.1055/s-0043-100019

Pang, S. C., Wang, S., Chen, M. L., Zhang, J. P., Wang, Y. Y., Jia, H. Y., et al. (2019). BuShenKangShuai Tablet Alleviates Hepatic Steatosis via Improving Liver Adiponectin Resistance in ApoE(-/-) Mice. Evid. Based. Complement. Alternat. Med. 2019, 8986038. doi: 10.1155/2019/8986038

Park, M., Yoo, J. H., Lee, Y. S., and Lee, H. J. (2019). Lonicera caerulea Extract Attenuates Non-Alcoholic Fatty Liver Disease in Free Fatty Acid-Induced HepG2 Hepatocytes and in High Fat Diet-Fed Mice. Nutrients 11, 494. doi: 10.3390/nu11030494

Peng, H., He, Y., Zheng, G., Zhang, W., Yao, Z., and Xie, W. (2016). Meta-analysis of traditional herbal medicine in the treatment of nonalcoholic fatty liver disease. Cell Mol. Biol. (Noisy-le-grand) 62, 88-95.

Porras, D., Nistal, E., Martinez-Florez, S., Pisonero-Vaquero, S., Olcoz, J. L., Jover, R., et al. (2017). Protective effect of quercetin on high-fat diet-induced nonalcoholic fatty liver disease in mice is mediated by modulating intestinal microbiota imbalance and related gut-liver axis activation. Free Radic. Biol. Med. 102, 188-202. doi: 10.1016/j.freeradbiomed.2016.11.037

Porras, D., Nistal, E., Martínez-Flórez, S., González-Gallego, J., García-Mediavilla, M. V., and Sánchez-Campos, S. (2018). Intestinal Microbiota Modulation in Obesity-Related Non-alcoholic Fatty Liver Disease. Front. Physiol. 9, 18131813. doi: 10.3389/fphys.2018.01813

Qi, G., Guo, R., Tian, H., Li, L., Liu, H., Mi, Y., et al. (2018). Nobiletin protects against insulin resistance and disorders of lipid metabolism by reprogramming of circadian clock in hepatocytes. Biochim. Biophys. Acta Mol. Cell Biol. Lipids 1863, 549-562. doi: 10.1016/j.bbalip.2018.02.009

Rahmani, S., Asgary, S., Askari, G., Keshvari, M., Hatamipour, M., Feizi, A., et al. (2016). Treatment of Non-alcoholic Fatty Liver Disease with Curcumin: A 
Randomized Placebo-controlled Trial. Phytother. Res. 30, 1540-1548. doi: $10.1002 /$ ptr.5659

Sanyal, A. J., Chalasani, N., Kowdley, K. V., Mccullough, A., Diehl, A. M., Bass, N. M., et al. (2010). Pioglitazone, Vitamin E, or Placebo for Nonalcoholic Steatohepatitis. New Engl. J. Med. 362, 1675-1685. doi: 10.1056/NEJMoa0907929

Sarwar, R., Pierce, N., and Koppe, S. (2018). Obesity and nonalcoholic fatty liver disease: current perspectives. Diabetes Metab. Syndr. Obes. 11, 533-542. doi: 10.2147/DMSO.S146339

Shen, L., Xiong, Y., Wang, D. Q., Howles, P., Basford, J. E., Wang, J., et al. (2013). Ginsenoside Rb1 reduces fatty liver by activating AMP-activated protein kinase in obese rats. J. Lipid Res. 54, 1430-1438. doi: 10.1194/jlr.M035907

Shen, K., Wang, Y., Zhang, Y., Zhou, H., Song, Y., Cao, Z., et al. (2015). Cocktail of Four Active Components Derived from Sheng Mai San Inhibits Hydrogen Peroxide-Induced PC12 Cell Apoptosis Linked with the Caspase-3/ROCK1/ MLC Pathway. Rejuvenation Res. 18, 517-527. doi: 10.1089/rej.2015.1697

Shi, K. Q., Fan, Y. C., Liu, W. Y., Li, L. F., Chen, Y. P., and Zheng, M. H. (2012). Traditional Chinese medicines benefit to nonalcoholic fatty liver disease: a systematic review and meta-analysis. Mol. Biol. Rep. 39, 9715-9722. doi: 10.1007/s11033-012-1836-0

Si, W., Chen, Y. P., Zhang, J., Chen, Z. Y., and Chung, H. Y. (2018). Antioxidant activities of ginger extract and its constituents toward lipids. Food Chem. 239, 1117-1125. doi: 10.1016/j.foodchem.2017.07.055

Solhi, H., Ghahremani, R., Kazemifar, A. M., and Hoseini Yazdi, Z. (2014). Silymarin in treatment of non-alcoholic steatohepatitis: A randomized clinical trial. Caspian J. Internal Med. 5, 9-12.

Song, C. Y., Shi, J., Zeng, X., Zhang, Y., Xie, W. F., and Chen, Y. X. (2013). Sophocarpine alleviates hepatocyte steatosis through activating AMPK signaling pathway. Toxicol. In Vitro 27, 1065-1071. doi: 10.1016/ j.tiv.2013.01.020

Tang, W., Zeng, L., Yin, J., Yao, Y., Feng, L., Yao, X., et al. (2015). Hugan Qingzhi Exerts Anti-Inflammatory Effects in a Rat Model of Nonalcoholic Fatty Liver Disease. Evidence-Based Complementary Altern. Med. 2015, 810369. doi: 10.1155/2015/810369

Van De Wier, B., Koek, G. H., Bast, A., and Haenen, G. R. (2017). The potential of flavonoids in the treatment of non-alcoholic fatty liver disease. Crit. Rev. Food Sci. Nutr. 57, 834-855. doi: 10.1080/10408398.2014.952399

Wang, Y.-L., Liu, L.-J., Zhao, W.-H., and Li, J.-X. (2015). Intervening TNF- $\alpha$ via PPAR $\gamma$ with Gegenqinlian Decoction in Experimental Nonalcoholic Fatty Liver Disease. Evidence-Based. Complement. Altern. Med. 2015, 715638. doi: $10.1155 / 2015 / 715638$

Wang, Y., Liu, Q., Xu, Y., Zhang, Y., Lv, Y., Tan, Y., et al. (2016). Ginsenoside Rg1 Protects against Oxidative Stress-induced Neuronal Apoptosis through Myosin IIA-actin Related Cytoskeletal Reorganization. Int. J. Biol. Sci. 12, 1341-1356. doi: $10.7150 /$ ijbs. 15992

Wang, Y., Xu, Y., Liu, Q., Zhang, Y., Gao, Z., Yin, M., et al. (2017). Myosin IIArelated Actomyosin Contractility Mediates Oxidative Stress-induced Neuronal Apoptosis. Front. Mol. Neurosci. 10, 75. doi: 10.3389/fnmol.2017.00075

Wang, S., Yang, F. J., Shang, L. C., Zhang, Y. H., Zhou, Y., and Shi, X. L. (2019a). Puerarin protects against high-fat high-sucrose diet-induced non-alcoholic fatty liver disease by modulating PARP-1/PI3K/AKT signaling pathway and facilitating mitochondrial homeostasis. Phytother. Res. 33, 2347-2359. doi: $10.1002 /$ ptr.6417

Wang, Y., Zhao, H., Li, X., Li, N., Wang, Q., Liu, Y., et al. (2019b). Tangshen Formula Alleviates Hepatic Steatosis by Inducing Autophagy Through the AMPK/SIRT1 Pathway. Front. Physiol. 10, 494. doi: 10.3389/fphys.2019.00494

Wat, E., Ng, C. F., Wong, E. C., Koon, C. M., Lau, C. P., Cheung, D. W., et al. (2016). The hepatoprotective effect of the combination use of Fructus Schisandrae with statin-A preclinical evaluation. J. Ethnopharmacol. 178, 104-114. doi: 10.1016/j.jep.2015.12.004

Wong, V. W.-S., Chan, R. S.-M., Wong, G. L.-H., Cheung, B. H.-K., Chu, W. C.-W., Yeung, D. K.-W., et al. (2013). Community-based lifestyle modification programme for non-alcoholic fatty liver disease: a randomized controlled trial. J. Hepatol. 59, 536-542. doi: 10.1016/j.jhep

Xiao, J., Ching, Y. P., Liong, E. C., Nanji, A. A., Fung, M. L., and Tipoe, G. L. (2013a). Garlic-derived S-allylmercaptocysteine is a hepato-protective agent in non-alcoholic fatty liver disease in vivo animal model. Eur. J. Nutr. 52, 179191. doi: 10.1007/s00394-012-0301-0
Xiao, J., Guo, R., Fung, M. L., Liong, E. C., Chang, R. C., Ching, Y. P., et al. (2013b). Garlic-Derived S-Allylmercaptocysteine Ameliorates Nonalcoholic Fatty Liver Disease in a Rat Model through Inhibition of Apoptosis and Enhancing Autophagy. Evid. Based. Complement Alternat. Med. 2013, 642920. doi: $10.1155 / 2013 / 642920$

Xiao, J., Xing, F., Huo, J., Fung, M. L., Liong, E. C., Ching, Y. P., et al. (2014). Lycium barbarum polysaccharides therapeutically improve hepatic functions in non-alcoholic steatohepatitis rats and cellular steatosis model. Sci. Rep. 4, 5587. doi: $10.1038 /$ srep05587

Xu, L., Yin, L., Tao, X., Qi, Y., Han, X., Xu, Y., et al. (2017). Dioscin, a potent ITGA5 inhibitor, reduces the synthesis of collagen against liver fibrosis: Insights from SILAC-based proteomics analysis. Food Chem. Toxicol. 107, 318-328. doi: 10.1016/j.fct.2017.07.014

Yan, T., Wang, H., Cao, L., Wang, Q., Takahashi, S., Yagai, T., et al. (2018). Glycyrrhizin Alleviates Nonalcoholic Steatohepatitis via Modulating Bile Acids and Meta-Inflammation. Drug Metab. Disposition 46, 1310-1319. doi: 10.1124/ dmd.118.082008

Yang, L., Ren, S., Xu, F., Ma, Z., Liu, X., and Wang, L. (2019). Recent Advances in the Pharmacological Activities of Dioscin. BioMed. Res. Int. 2019, 5763602. doi: $10.1155 / 2019 / 5763602$

Yang, X. X., Wang, X., Shi, T. T., Dong, J. C., Li, F. J., Zeng, L. X., et al. (2019). Mitochondrial dysfunction in high-fat diet-induced nonalcoholic fatty liver disease: The alleviating effect and its mechanism of Polygonatum kingianum. BioMed. Pharmacother. 117, 109083. doi: 10.1016/j.biopha.2019.109083

Yang, Y., Li, J., Wei, C., He, Y., Cao, Y., Zhang, Y., et al. (2019). Amelioration of nonalcoholic fatty liver disease by swertiamarin in fructose-fed mice. Phytomedicine 59, 152782. doi: 10.1016/j.phymed.2018.12.005

Yao, Z., Liu, X. C., and Gu, Y. E. (2014). Schisandra chinensis Baill, a Chinese medicinal herb, alleviates high-fat-diet-inducing non-alcoholic steatohepatitis in rats. Afr. J. Tradit. Complement. Altern. Med. 11, 222-227. doi: 10.4314/ ajtcam.v11i1.35

Yao, H., Qiao, Y.-J., Zhao, Y.-L., Tao, X.-F., Xu, L.-N., Yin, L.-H., et al. (2016). Herbal medicines and nonalcoholic fatty liver disease. World J. Gastroenterol. 22, 6890-6905. doi: 10.3748/wjg.v22.i30.6890

Yao, H., Tao, X., Xu, L., Qi, Y., Yin, L., Han, X., et al. (2018). Dioscin alleviates non-alcoholic fatty liver disease through adjusting lipid metabolism via SIRT1/ AMPK signaling pathway. Pharmacol. Res. 131, 51-60. doi: 10.1016/ j.phrs.2018.03.017

Yin, J., Luo, Y., Deng, H., Qin, S., Tang, W., Zeng, L., et al. (2014). Hugan Qingzhi medication ameliorates hepatic steatosis by activating AMPK and PPAR $\alpha$ pathways in L02 cells and HepG2 cells. J. Ethnopharmacol. 154, 229-239. doi: 10.1016/j.jep.2014.04.011

Yu, X., Ye, L., Zhang, H., Zhao, J., Wang, G., Guo, C., et al. (2015). Ginsenoside $\mathrm{Rb} 1$ ameliorates liver fat accumulation by upregulating perilipin expression in adipose tissue of db/db obese mice. J. Ginseng Res. 39, 199-205. doi: 10.1016/ j.jgr.2014.11.004

Yuanyuan, W., Minghua, J., Lina, Z., Suhua, L., Jiayu, Z., Yongzhi, S., et al. (2015). Effect of a combination of calorie-restriction therapy and Lingguizhugan decoction on levels of fasting blood lipid and inflammatory cytokines in a high-fat diet induced hyperlipidemia rat model. J. Tradit. Chin. Med. 35, 218221. doi: 10.1016/S0254-6272(15)30031-5

Yuk, T., Kim, Y., Yang, J., Sung, J., Jeong, H. S., and Lee, J. (2018). Nobiletin Inhibits Hepatic Lipogenesis via Activation of AMP-Activated Protein Kinase. Evid. Based. Complement. Alternat. Med. 2018, 7420265. doi: 10.1155/2018/ 7420265

Zhai, K., Tang, Y., Zhang, Y., Li, F., Wang, Y., Cao, Z., et al. (2015). NMMHC IIA inhibition impedes tissue factor expression and venous thrombosis via Akt/ GSK33-NF-KB signalling pathways in the endothelium. Thromb. Haemostasis 114, 173-185. doi: 10.1160/TH14-10-0880

Zhang, Q., Zhao, Y., Zhang, D.-B., and Sun, L.-J. (2005). Effect of Sinai san decoction on the development of non-alcoholic steatohepatitis in rats. World J. Gastroenterol. 11, 1392-1395. doi: 10.3748/wjg.v11.i9.1392

Zhang, Y., Si, Y., Zhai, L., Yang, N., Yao, S., Sang, H., et al. (2013). Celastrus orbiculatus Thunb. ameliorates high-fat diet-induced non-alcoholic fatty liver disease in guinea pigs. Pharmazie 68, 850-854.

Zhang, Y., Chen, M. L., Zhou, Y., Yi, L., Gao, Y. X., Ran, L., et al. (2015). Resveratrol improves hepatic steatosis by inducing autophagy through the 
cAMP signaling pathway. Mol. Nutr. Food Res. 59, 1443-1457. doi: 10.1002/ mnfr.201500016

Zhang, E., Yin, S., Song, X., Fan, L., and Hu, H. (2016). Glycycoumarin inhibits hepatocyte lipoapoptosis through activation of autophagy and inhibition of ER stress/GSK-3-mediated mitochondrial pathway. Sci. Rep. 6, 38138. doi: $10.1038 /$ srep38138

Zhang, W., Yin, L., Tao, X., Xu, L., Zheng, L., Han, X., et al. (2016). Dioscin alleviates dimethylnitrosamine-induced acute liver injury through regulating apoptosis, oxidative stress and inflammation. Environ. Toxicol. Pharmacol. 45, 193-201. doi: 10.1016/j.etap.2016.06.002

Zhang, J., Zhang, H., Deng, X., Zhang, N., Liu, B., Xin, S., et al. (2018). Baicalin attenuates non-alcoholic steatohepatitis by suppressing key regulators of lipid metabolism, inflammation and fibrosis in mice. Life Sci. 192, 46-54. doi: 10.1016/j.lfs.2017.11.027

Zhang, Y., Tang, K., Deng, Y., Chen, R., Liang, S., Xie, H., et al. (2018). Effects of shenling baizhu powder herbal formula on intestinal microbiota in high-fat diet-induced NAFLD rats. BioMed. Pharmacother. 102, 1025-1036. doi: 10.1016/j.biopha.2018.03.158
Zhou, L., Tang, J., Xiong, X., Dong, H., Huang, J., Zhou, S., et al. (2017). Psoralea corylifolia L. Attenuates Nonalcoholic Steatohepatitis in Juvenile Mouse. Front. Pharmacol. 8, 876. doi: 10.3389/fphar.2017.00876

Zhu, X., Bian, H., Wang, L., Sun, X., Xu, X., Yan, H., et al. (2019). Berberine attenuates nonalcoholic hepatic steatosis through the AMPK-SREBP-1c-SCD1 pathway. Free Radic. Biol. Med. 141, 192-204. doi: 10.1016/j.freeradbiomed.2019.06.019

Conflict of Interest: The authors declare that the research was conducted in the absence of any commercial or financial relationships that could be construed as a potential conflict of interest.

Copyright $\odot 2020 \mathrm{Xu}$, Guo, Zhang, Chen, Tan, Li, Wang and Feng. This is an openaccess article distributed under the terms of the Creative Commons Attribution License (CC BY). The use, distribution or reproduction in other forums is permitted, provided the original author(s) and the copyright owner(s) are credited and that the original publication in this journal is cited, in accordance with accepted academic practice. No use, distribution or reproduction is permitted which does not comply with these terms. 